\title{
I. Ueber die geometrischen Eigenschaften homogener starrer Structuren und ihre Anwendung auf Krystalle.
}

\author{
Von \\ William Barlow in London.
}

(Hierzu Taf. I und II.)

Es ist der Gegenstand dieser Abhandlung, die Art der Anordnung gleichartiger Theile in homogenen Structuren im Allgemeinen ohne Bezugnahme auf irgend eine Atom- oder Krystaltheorie zu untersuchen und auf diese Weise ein rein geometrisches Fundament zu légen, das allen Theoretikern eine gemeinschaftliche Grundlage zu bieten im Stande ist.

Man wird finden, dass die Resultate dieser Untersuchung feststellen, dass in jeder homogenen Structur von irgend welcher Art gleichartige Punkte eine symmetrische Anordnung von einem bestimmten, der Structur eigenthumlichen Typus besitzen, und dass alle Symmetriearten, die von allen beliebigen bomogenen Structuren dargeboten werden, in 32 Classen zerfallen, deren unterscheidende Merkmale genau jene der 32 geometrischmöglichen Classen der Krystallsymmetrie sind $\left.{ }^{*}\right)$.

Es wird ferner gezeigt werden, dass die 65 regelmässigen, in So h n c k e's "Entwickelung einer Theorie der Krystallstructur " beschriebenen Punktsysteme aus zehn Fundamentalsystemen aufgebaut sind ${ }^{*}$ ).

Ein kleiner Raum wird der Untersuchung singulärer Punktsysteme, $d$. h. solcher von besonderer Symmetrie gewidmet werden, welche in allen homogenen Structuren vorhanden sind.

Definition: Eine homogene starre Structur isteine Anordnung von beliebig beschaffener Malerie constanter Form, die sich gleichförmig in ihrer ganzen Ausdehnung immer wiederholt. Präciser: Es ist eine starre Structur, in welcher jeder

*) Siehe Gadolin, Acta soc. Fennicae 9, Helsingfors 1871 oder Sohncke, diese Zeitschr. 20, 457.

**) Entwickelung einer Theorie der Krystallstructur von Dr. Leonh. Sohncke, Leipzig 1879.

Groth, Zeitschrift f. Krystallogr. XXIII. 
Punkt, wenn wir die Structur als unbegrenzt denken, ihmentsprechend andere genau gleichartige oder homologe Punkte*) besitzt, die gleichförmig im Raume vertheilt sind; es ist daher eine Eigenschaft der Structur, dass alle die unendlichvielen geometrischen Punktsysteme, welche beziehungsweise gegeben sind, wenn man allegleicharligen Punktenimmt, regelmässige unendliche Punktsystemesind, wiesie Sohnckedefinirt als ssolche, bei welchen um jeden Massenpunkt herum die Anordnungder ubrigendieselbeist, wie um jeden anderen Massenpunkt (**) $^{*}$.

Ein Haufen gleicher Kanonenkugeln; in welchem jede Kugel «wölf andere berührt, ist ein triviales Beispiel einer solchen Structur.

Man wähle nun auf's Geradewohl einen geometrischen Punkt irgendwo in einem solchen Haufen und markire den ihm zunächst gelegenen Kugelmittelpunkt. Dann giebt es im Allgemeinen 23 andere Punkte, welche von diesem Centrum den gleichen Abstand wie der gewählte haben, und einen gleichen Ort im Haufen einnehmen, so dass der Kugelhaufen, als unbegrenzt und ohne Rücksicht auf die Richtung betrachtet, genau denselben Anblick zeigt, wenn er vom einen oder anderen der 24 Punkte aus gesehen wird. Diese Punkte bilden einen "24-Punkter", den Sohncke in seinem oben erwähnten Werke beschreibt***).

*) Gleicharlige Punkte sind solche, welche gleichartige Orte innerhalb der Structur einnehmen, wenn diese als unendlich und obne Rücksicht auf die Richtung betrachtet wird, oder mit anderen Worten: Punkte, von deren jedem aus gesehen die als unendlich und ohne Bezug auf irgend etwas anderes als auf sie selbst betrachtete Structur genau denselben Anblick darbietet.

**) Entwickelung einer Theorie elc. S. 28. Vergl. M. C. Jordan, "Sur les groupes de mouvements «, Comples rendus 1867, 65, 229.

Die Starrheit der eben definirten Structur braucht keine absolute zu sein, es können Schwingungs- oder andere Bewegungen ihrer kleinsten Theile stattfinden, wie sie in allen bekaunten festen Körpern vorkommen; der obigen Definilion wird genügt, so lange die Bewegungen an entsprechenden Punkten im Ganzen gleichartig sind und nicht so, dass sie die relative Lage gleichartiger Theile bleibend verändern. Uebereinstimmend mit der Definition kann eine homogene Structur aus einer beliebigen Anzahl verschiedener, in irgend einer Weise angeordneter Stoffe bestehen, wenn nur ihre Anordnung der Definition genügt.

Die Frage, ob der Gebrauch des Wortes homogen in der eben gegebenen Definition berechtigt ist oder nicht, berührt die folgenden Beweisführungen nicht; wenn man will, kann man irgend ein anderes Wort anwenden, um die hier definirte Gleichheit der Theile auszudrücken. Es mag jedoch bemerkt sein, dass die gegebene Definition allen Anforderungen an die Gleichbeit entsprechender Theile genügl, so lange die Structur für sich allein, obne Bezug auf etwas Anderes betrachtet wird.

Das Wort "Structur " ist gewählt, um anzudeuten, dass die kleinsten Theile oder Raumeinheiten dreidimensional sind, und dass keine ihrer drei Dimensionen unendlich ist.

***) Entwickelung einer Theorie etc., S. 166. 
Ferner können 24, mit jenen gleichartige Punkte gefunden werden, welche um jedes der anderen Kugelcentren gelagert sind, und die Punkte aller solcher gleichartiger Gruppen liefern zusammen genommen ein Beispiel zu Sobncke's System 60 (ok taëdrisches 24-Punktersystem) *).

Indem Sohncke's Definition der regelmässigen unendlichen Punktsysteme die Homogenität der Anordnung bedingt, setzt sie nicht prima facie eine bestimmte Symmetrie voraus. Wenn jedoch alle möglichen Typen der unendlichen**) regelmässigen Punktsysteme aufgesucht werden, was in Sohncke's eben angefuhrtem Werke geschehen ist, so zeigl sich, dass die $\left.65^{* * *}\right)$ verschiedenen Typen der unendlichen Punktsysteme, welche allein seine Definition erfülen, alle -eine bestimmte Symmetrie haben, welche genau einigen der bei Krystallen vorkommenden Symmetrietypen entsprechen.

Eine homogene Structur besitzt jedoch oft einen höheren Grad von Symmetrie, als jener des grössten Theiles der So b ncke'schen Punktsysteme, welche durch ihre gleichartigen Punkte bestimmt sind. Ein Beispiel hierfur liefert der eben erwähnte Kugelhaufen.

Andererseits zeigt zuweilen eine homogene Structur einen niedrigeren Grad der Symmetrie als jenen ihrer Sohncke'schen Punktsysteme. Beispiele hierfur werden unten gegeben $\dagger$ ).

Wo eine homogene Structur einen höheren Grad von Symmetrie zeigt als jenen, der den meisten Sohncke'schen Punktsystemen zukommt, welche durch ihre gleichartigen Punkte bestimmt sind, da wird man immer finden, dass sie diese höhere Symmetrie dem Besitze folgender Eigenschaft neben der Eigenschaft der Homogenität verdankt: Die Structur ist nämlich identisch mit ihrem eigenen Spiegelbilde t+).

*) Entsprechend jedem regelmässigen Punktsysteme, welches so durch gleichartige Punkte gegeben ist, giebt es in einem solchen Haufen ein anderes Punktsystem, welches das Spiegelbild desselben ist, da die Punkle eines jeden der beiden Systeme in. gleicher Entfernung von den Kugelcentren gelegen sind und das Bild der SIructur von einem Punkte des einen Systems das Spiegelbild seiner Ansicht von einem Punkte des anderen Systems desselben Paares ist. Wir kümmern uns jetzt jedoch nicht um jene spiegelbildlich-gleichen Punktsysteme; sie werden später behandelt (siehe S. 38).

**) Mit endlichen Punklsystemen, bestehend aus Punkten, welche eine solche Gleichartigkeit besitzen, wie sie eben definirt wurde, beschäftigen wir uns hier nicht; sie zeigen offenbar keine stetige Wiederholung derselben Structur nach jeder Richtung.

Bezüglich einer Untersuchung dieser endlichen Systeme siebe Jor dan's oben citirtes Werk.

***) So hnck e erwähnt in seinem Werke 66, hat aber nachher darauf hingewiesen, dass es nur 65 giebt, da Nr. 9 und Nr. 13 einander gleich sind. Siehe diese Zeitschr. 14, 4.23 .

t) Siehe S. 25, 29, 32, 37.

$+t$ ) Man wird finden, dass dies bei allen homogenen Structuren der Fall ist, welche holoëdrische und einige andere höhere Symmetriearten besitzen. 
Die Art der Beziehungen, welche zwischen den Sohncke'schen Punktsystemen einer homogenen Structur bestehen, wenn letztere diese neve Eigenschaft besitzt, wird alsbald untersucht werden, nachdem die Eigenschaften der Punktsysteme selbst betrachtet worden sind *).

Was die Eigenschaften betriff, welche homogene Structuren mit den, durch ihre gleichartigen Punkte bestimmten Punktsystemen gemein haben, bemerken wir, dass irgend eine gegebene homogene starre Structur, wie oben definirt, gleich den S o hncke'schen Systemen gewisser Deckbewegungen **) făhig sein wird, welche, indem sie irgend eine besondere Scbaar entsprechender Punkte zur Deckung bringen, zu gleicher Zeit alle verschiedenen entsprechenden Theile der Structur zur Deckung bringen; es ist dies eine directe Folge der genau gleichen Lage, welche entsprechende Punkte in Bezug auf die ganze Structur besitzen. Und es ist klar, dass die Deckbewegungen, welche fur die Structur als Ganzes moglich sind, auch für all die unendlich vielen regelmässigen Punktsysteme möglich sind, welche durch Schaaren entsprechender. Punkte der Structur bestimmt sind, und dass die Structur, als Ganzes genommen, jene Deckbewegungen besitzen wird, welche allen versehiedenen, so bestimmten Punktsystemen gemein s a sind.

Ferner wird die successive Ausfubrung jener Deckbewegungen in jedem Falle binreichend sein, um einen beliebigen Punkt der Structur an die Stelle eines beliebigen anderen gleichartigen Punktes zu bringen. Und da im Allgemeinen ein auf die angegebene Weise bestimmtes Punksystem, selbst wenn es obne Rucksicht auf die Structur, zu welcher es gehört, be-

*) Siebe S. 38.

**) Eine Deckbewegung definirt S o hncke folgendermassen : "Man denke sich nun ein regelmåssiges, unendliches Punktsystem starr gemacht und aus seiner Lage herausgerückt; dann bilden die zuvor von Systempunkten besetzt gewesenen Orte des Raumes ein dem System congruentes Punktsystem; es möge, im Gegensatze zu dem herausgenommenen beweglichen Systeme, das feste heissen. In welchen Systempunkt des festen Systems man nun einen beliebig gewählten Systempunkt des beweglichen auch legen mag: immer kann man in Folge der Congruenz aller Linienbündel bewirken, dass beide Systeme zur Deckung gelangen. Eine solche Bewegung nun, welchedas bewegliche System auseiner Lage derDeckung mitdem festen in eine andere Lage der Deckung mit ihm überführt, soll eine Deckbewegung beissen. Diese Bewegungen können theils Parallelverschiebungen, theils Drehungen oder Schraubungen um gewisse, im festen Systeme gegebene gerade Linien als Axen sein; und es wird ganz von der Eigentbümlichkeit des betreffenden Systems abhängen, welcherlei Deckbewegungen es besitzt. Ja man wird gerade nach den ihnen zukommenden Deckbewegungen verschiedene Gattungen von Punktsystemen unterscheỉen können, so dass die verschiedenen Arten von Deckbewegungen als Eintheilungsgrund für die regelmassigen Punktsystemedienen." (Siehe Entwickelüng einer Theorie eti. S. 28.) Vergl. Bravais „Sur les systèmes formés par des points distribués régulièrement ", Journ. de l'Ecole Polytechnique, cahier XXXIII; p. 57. 
Ueber die geometrischen Eigenschaften bomogener starrer structurentethek 5 trachtet wird, keine anderen Deckbewegungen fferfefikx sukommen, besitzen wird, so ist klar, dass jede homogene starre Structur die Deckbewegungen eines der 65 Sohncke'schen Punktsysteme und keine anderen*) besitzt.

\section{Die Sohncke'schen Systeme und homogenen Structuren, welche n i h t mit ihren eigenen Spiegelbildern identisch sind.}

Es ist deshalb wichtig zu ermitteln, welche Beziehungen zwischen regelmässigen Punksystemen verschiedener Typen bestehen, und es soll zunächst gezeigt werden, dass jedes der 65 Sohncke'schen Punktsysteme aus einer endlichen Anzahl eines oder desanderen von zebn Fundamentalsystemen besteht. Diese Fundamentalsysteme gehören den Typenan, welche Sohnckebezeichnet als System 58, 42 und 43, 26 und 27, 15 und 16, einspecieller Fall von System 3, System 3 und System 1 .

Dabei werden auch einfache Methoden angegeben werden, die Sohncke'schen Systeme zu erhalten.

In allen Fällen wird festgestellt werden, zu welcher der 32 Classen der Krystallsymmetrie jeder Typus der Soh n cke'schen Systeme und jeder Typus der homogenen Structur, deren Symmetrie untersucht wird, gehört.

\section{Die reguläre Systemgruppe.}

Zunächst soll in Hinsicht auf Systeme der regulären Form, d. h. jener unter VI und VII der Uebersichtstabelle auf S. 175 in Sohncke's Werk, gezeigt werden, dass jedes dieser 13 Systeme betrachtet werden kann als bestehend aus einer endlichen Anzahl untereinander identischer Systeme eines gewissen Musters, nämlich des als System $\mathbf{5 8}$ in der Uebersichtstabelle bezeichneten; und auch, dass jedes der 13 Systeme die Axen und Deckbewegungen des Systems besitzt, aus welchem dasselbe aufgebaut ist.

Genauer gesagt :

Typus $1=$ System 58 nach Sohncke.

Typus 2 (System 57) kann betrachtet werden als das Product der

*) So sind z. B. die Deckbewegungen des eben beschriebenen Kugelhaufens jene des Systems 60 von Sobncke.

In seiner Erweiterung der Theorie der Krystallstructur (diese Zeitschr. 14, 433 und 434) weist Sohncke darauf hin, dass ineinander gestellte homogene Combinationen seiner regelmässigen Punktsysteme alle Arten der in Krystallen vorkommenden Symmetrie liefern werden. Um hom ogenzu sein, müssendiese Combinatione n so a usgedacht sein, dass siediehierdargelegten Eigenschafteneiner homogen.en Structurbesitzen. 
Ineinanderstellung zweier mit einander identischer Systeme des Typus 1; die Axen und Deckbewegungen dieser Theilsysteme sind uberdies dem zusammengesetzten System eigen.

Typus 3 und 4 (System 65 und 66) bestehen ebenfalls je aus zwei solchen Systemen, die dieselbe Beziehung zu dem zusammengesetzten System haben.

Typus 5 (System 62) besteht aus vier.

- 6 (System 55) besteht ebenfalls aus vier.

- 7 (System 54)

- 8 (System 60) besteht aus acht.

- 9 (System 63)

- 10 (System 56)

- 11 (System 64) aus sechzehn.

- 12 (System 59)

- 13 (System 61) aus zweiunddreissig.

Die zum Beweise des eben ausgesprochenen Satzes und ähnlicher Sätze, welche bezuglich der ubrigen der $65 \mathrm{~S}$ oh ncke'schen Typen folgen, angewendete Methode ist die folgende:

Jeder der 65 Typen von Sohncke hat seine charakteristischen Bewegungen. Die Ausführung einer derselben bringt Deckung hervor, und wenn alle nach einander einem irgendwo im Raume gelegenen Punkte ertheilt werden, so bewirken sie, dass dieser Punkt ein Punktsystem des Typus erzeugt, dem diese Bewegungen zukommen.

Wenn nun ein besonderes System das Ergebniss der Combination zweier oder mehrerer anderer identisch gleicher Systeme ist und die Axen und Deckbewegungen dieser Systeme besitzt, so ist klar, dass das zusammengesetzte System ausser diesen Deckbewegungen noch andere besitzen wird, welche geeignet sind, die Theilsysteme mit einander zur Deckung zu bringen.

Um also zu beweisen, dass irgend ein specielles Syslem aus einer gewissen Anzahl von Systemen eines anderen Typus besteht, welche auf gewisse Art angeordnet und in der bescbriebenen Weise mit ihm verwandt sind, werden wir die Deckbewegungen all dieser letzteren, sowie die verschiedenen Deckbewegungen nehmen, welche diese Theilsysteme zur Deckung mit einander bringen, und zuerst beweisen, dass das zusammengesetzte System alle jene Deckbewegungen besitzt, und dann zeigen, dass dies die charakteristischen Deckbewegungen des in Rede stehenden besonderen Punktsystemes sind.

Un dieses Beweisverfahren mit Leichtigkeit im Falle der Systeme der regulären Form auszufuhren, werden wir folgende einfache geometrische Metbode der Schilderung eines Systemes des Typus 1 ( 58 nacb Sohncke) mit seinen Axen und Deckbewegungen anwenden. 
Man theile den Raum durch drei Schaaren paralleler, äquidistanter Ebenen in gleiche Wurfel.

Man ziehe eine einzelne Diagonale in einem der Würfel. Wenn dies geschehen, bildet sie die gemeinschaftliche Diagonale eines Stranges von Würfeln, die mit den körperlicben Ecken zusammenstossen.

Durch einen zweiten Würfel, der eine Fläche mit dem ersten gemein hat, ziehe man eine einzelne Diagonale, welche die Diagonale im ersten Würfel nicht schneidet und nicht parallel zú ibr ist. Diese bildet dann auch die gemeinschaftliche Diagonale eines Würfelstranges.

In Syslemen des Typus 1 (58 nach Sobncke) schneiden sich die dreizähligen Axen nicht. Man nehme nun die zwei so gezogenen Diagonalen, deren Richtungen offenbar unter dem verlangten Winkel gegen einander geneigt sind, als zwei benachbarte dreizählige Axen eines Systems von diesem Typus.

Man fưbre eine dreizählige Drehung um eine dieser Axen aus, so dass die aufeinander folgenden Lagen, welche die andere Axe annimmt, zwei neue Lagen für dreizählige Axen bestimmen werden, und indem man weitere dreizählige Drehungen um die nach und nach gefundenen dreizähligen Axen ausführt, erhält man in gleicher Weise andere ähnliche Axen, so dass man schliesslich ein unendliches System dreizähliger Axen bekommt, deren jede eine Linie ist, die aus aneinander gereihten Würfeldiagonalen besteht.

Nur ein einziges solches System dreizähliger Drehaxen kann aus den zwei zuerst gezogenen Axen erzeugt werden. Keine zwei seiner dreizähligen Axen schneiden sich. Es ist ferner ein homogenes System nach der oben gegebenen Definition der Homogenität.

Dieses System dreizähliger Axen wird daher in dem fraglichen System vorkommen; in der That muss offenbar ein solches System in allen homogenen Structuren oder Systemen der regulären Form vorhanden sein, deren dreizählige Axen sich nich t schneiden. Seine Gestaltkann folgendermassen beschrieben werden.

Da die dreizähligen Drehaxen sich nicht schneiden, so kann nur eine der vier Diagonalen eines beliebigen Würfels eine solche Axe sein, und wir können daher die Würel durch die Buchstaben $\alpha, \beta, \gamma, \delta$ unterscheiden, je nach der Bichtung, in welcher sie von einer dreizähligen Drehaxe durchquert werden. Die punktirten Diagonalen in Fig. 1 sollen die vier Lagen der dreizähligen Axen in den so bezeichneten Würfeln zeigen.

In Fig. 2 seien $\alpha, \beta$ zwei zusammenstossende Würfel, in welchen die in dieser Weise angedeuteten Diagonalen zwei nächste dreizäblige Drehaxen eines solchen Systems von Drehaxen sind. Màn sieht nun leicht, dass, wenn successive dreizählige Drehungen in der geschilderten Weise ausgefübrt werden, das System von Wüfeln folgendermassen von den Drehaxen: durchkreuzt wird : 
Die Würfelschicht, welche die Wurfel $\alpha$ und $\beta$ enthält, wird von den dreizähligen Drehaxen so durchsetzt werden, wie es die griechischen Buchstaben in Fig. 2 anzeigen.

Unmittelbar unter und unmittelbar über dieser Schicht wird eine Schicht liegen, welche so durchschnitten wird, wie die griechischen Buchstaben in Fig. 3 zeigen. Denselben werden wieder wie in Fig. 2 durchsetzte Schichten folgen.

So wird das ganze System der Würel und Drehaxen aus Schichten bestehen, die abwechselnd diesen beiden Gattungen angehören.

Wir können nun ein Punktsystem des,Typus 1 (58 nach Sohncke) um das eben beschriebene System dreizähliger Axen wie folgt construiren:

Man nehme ganz beliebig einen Punkt in diesem Axensystem, markire den Wurfel, in welchem der Punkt liegt und durch eine Drehung um die einzige, diesen Wurfel durchlaufende dreizählige Axe findet man in dem Wurfel zwei andere Punkte, welche mit dem ursprünglichen eine gleichzeitige Punkttriade bilden.

Durch eine Drehung um die dreizählige Axe, welche einen der sechs Wurfel durchläuft, die mit dem eben erwähnten Würfel eine Fläche gemeinsam haben, bringe man eine entsprechende Punkttriade in jeden der beiden Wüfel, welche den ersten Würfel in zwei seiner Kanten berühren. Man füre eine Reihenfolge anderer dreizäbliger Drehungen um die Axen, welche andere Würfel durchsetzen, aus, bis jeder Würfel, welcher dadurch schliesslich mit den die Triaden entbaltenden Wurfeln zur Deckung gebracht werden kann, eine entsprechende in ihm gelegene Punkttriade besitzt.

Das Ergebniss ist die Erzeugung eines regelmässigen Punktsystems, welches aus gleichen Punkttriaden besteht, je eines in jedem Würfel eines zusammenhängenden Systems von Würfeln gelegen, die nur mit den Kanten an einander stossen, d. h. ein symmetrisches System, welches die Hälfte aller den Raum erfüllenden Würfel umfasst*). Dieses Punkisystem ist das verlangte.

Um seine Identität mit dem genannten Punktsystem zu zeigen, können wir folgendermassen verfahren.

Die resultirende Bewegung irgend zweier Deckbewegungen eines beliebigen, regelmässigen geometrischen Systems ist ebenfalls eine Deckbewegung dieses Systems ${ }^{*}$ ).

Nun besitzt das eben untersuchte System folgende Deckbewegungen:

*) Die zwei halben Systeme der so angeordneten Würfel werden kenntlich gemacht, wenn schwarze und weisse gleich grosse Würfel so ohne Zwischenraum zusammengeschichtet werden, dass der Haufen längs Ebenen parallel zu den Würfelflächen das Aussehen eines Schachbrettes zeigt.

*) Siehe Entwickelung einer Theorie etc., kinematische Hülfsbetrachtung $1 \mathrm{X}$, S. a5. 
1. Eine dreizáhlige Drehung gegen den Drehsinn des Uhrzeigers um eine Axe, welche einen Wurfel $\beta$ in der in Fig. 2 dargestellten Würfelschicht durchläuft, und welche den diesem Würfel $\beta$ in derseJben Schicht (in der Figur) nach oben nächslliegenden Würfel $\alpha$ an die Stelle des Wurfels $\gamma$ bringt, der in der nächsthöheren Schicht uber dem Wurfel $\beta$ liegt.

2. Eine dreizählige Drehung gegen den Drehsinn des Uhrzeigers um die dreizäblige Axe dieses Würfels $\gamma$.

Man sieht leicht, dass die Resultirende dieser beiden Drehungen eine zweizählige Schraubung $\frac{A_{2 \pi}}{2}, a$ ist um eine zu den Ebenen der Fig. 2 und 3 senkrechte Axe in einem Punkte $A$, wenn $a$ die Länge der Wurfelkante.

Daher ist die erwähnte Schraubung eine Deckbewegung des eben verfolgten Systems. Und da alle durch die Punkte $A$ der erwähnten Figuren gezogenen Senkrechten jener Wurfelschichten zu dem Punktsystem genau in der gleichen Beziehung stehen, so folgt wegen der Symmetrie, dass gleiche Schraubungen vorhanden sind um Axen, welche senkrecht auf den Ebenen der Fig. 2 und 3 durch alle Punkte $A$ gelegt sind.

In ähnlicher Weise können wir das Vorhandensein gleicher Axon in Punkten $B, C$ und $D$ feststellen, welche zusammen mit $\operatorname{den}$ Axen $A$ vier Schaaren zweizähliger Schraubungen senkrecht zu Zeichnungsebene der Fig. 2 und 3 bilden. Ebenso die Existenz gleicher, aus je vier Gruppen bestehender Axensysteme, welche in je einer der beiden anderen Richtungen senkrecht zu den Würfelflächen liegen.

Nur Systeme des Typus 1 ( 58 nach Sohncke) besitzen zweizählige Schraubenaxen in drei zu einander senkrechten Richtungen, wobei vier Gruppen dieser Axen in jeder dieser drei Richtungen liegen und die Axen genau wie im Falle des vorliegenden Systems angeordnet sind. Es ist dasselbe daher ein System des Typus 1.

Um die Identität der beiden Typen bequemer veranschaulichen $\mathrm{zu}$ können, ist eine Copie von Sohncke's Figur des Theilsystems seines Systems 58 beigefugt (Fig. 4), mil der Projection der Würfelflächen, welche als punktirte Linien darin angegeben sind, und mit den Schnittpunkten jener zweizähligen Schraubenaxen, welche senkrecht zur Zeichnungsebene stehen, entsprechend mit $A, B, C, D$ bezeichnet, wie in den Fig. 2 und 3.

Nachdem wir so gezeigt haben, dass das oben geschilderte System ein System des Typus 1 (58 nach Sohncke) ist, können wir nun dázu übergehen, zu beweisen, dass ein System des Typus 2 ( 57 nach Sohncke) als das Ergebniss der Ineinanderstellung zweier mit einander identischer Systeme des Typus 1 angesehen werden kann, indem die Axen und Deckbewegungen der beiden Theilsysteme ubereinstimmen und also auch dem zusammengesetzten Systeme angehören. 
Um ein System vom Typus 2 aus einem Sysleme des Typus 1 abzuleiten, können wir folgende Constructionsmethode anwenden:

Durch irgend einen der Punkte E, F, G, $H$ der Fig. 2 und 3 denke man sich eine Senkrechte auf den Ebenen dieser Figuren errichtet, und fuhre eine zweizahlige Drehung um diese Senkrechte als Axe eines Punktsystems vom Typus 1 mit seinen Würfeln und Axen aus.

Die Folge davon isl, wie schon aus den erwähnten Figuren ersichtlich, dass die dreizähligen Drehaxen zur Deckung gelangen, und folglich auch die verschiedenen zweizähligen Schraubungen, deren Existenz ja, wie wir gesehen, durch das Vorhandensein jener dreizähligen Drehaxen beding ist.

Das Würfelsystem ist gleichzeilig mit sich selbst zur Deckung gebracht worden, aber das Halbsystem der Würfel, welche die Triaden enthalten, welche ein System vom Typus 1 bilden, kommt nicht mit sich selbst zur Deckung, sondern fällt mit dem anderen Halbsystem der Würfel zusammen, welche mit den ersten eine Fläche gemein haben.

Die Triaden, welche ursprünglich in dem einen Halbsystem der Würfel vorhanden waren, finden sich daher nun in gleicher Weise im complementären Halbsystem angeordnet. Die beiden so erhaltenen identischen Punktsysteme haben dieselben Axen, und das aus beiden zusammengeselzte System besitzt also auch diese Axen und hat ausserdem zweizählige Drehaxen senkrecht zur Zeichnungsebene durch die Punkte $E, F, G, H$ in Fig. 2 und 3. Wegen der Symmetrie ist leicht zu sehen, dass es auch Schaaren gleichartiger Drehaxen besitzt, welche in jeder der beiden anderen, zu den Würfelflächen senkrechten Richtungen liegen.

Dieses zusammengesetzte System, welches aus der beschriebenen Ineinanderstellung zweier Systeme vom Typus 1 resultirt, ist ein Beispiel vom Typus 2 ( 57 nach Sohncke).

Seine Identität mit einem Punktsystem vom genannten Typus wird durch die Thatsache bewiesen, dass die relative Lage entsprechender Schrauben- und Drehaxen in beiden dieselbe ist.

Um diese Identität besser veranschaulichen zu können, ist eine Copie von Sohncke's Figur eines Theilsystems vom System $\mathbf{5 7}$ beigefugt (Fig. 5) mit den Projectionen der Würfelflächen, welche als punktirte Linien darin zu sehen sind, und mit den Schniltpunkten jener zweizähligen Schraubenaxen $A, B, C, D$, welche senkrecht auf der Zeichnungsebene stehen, sowie der zweizähligen Drehaxen, $E, F, G, H$, entsprechend bezeichnet wie in Fig. 2 und 3.

Wir wollen nun dazu ubergehen, nachzuweisen, dass ein System, welches ein Beispiel zum Typus 3 oder 4 ( 65 und 66 nach Sohncke) ist, als das Resultat der Ineinanderstellung zweier mit einander identischer Systeme vom Typus 1 (58 nach Sohncke) betrachtet werden kann, indem 
die Axen und Deckbewegungen der zwei Theilsysteme coincidiren und also auch dem zusammengesetzten Systeme zukommen.

Durch die Mittelpunkte der Wurfel, in welche der Raum, wie oben*), getheilt worden ist, lege man Ebenen parallel zu den drei zuerst gelegten Schaaren von Ebenen. Die Folge davon ist eine neue Theilung des Raumes in Würfel, identisch mit der früheren Theilung, aber die Wurfelmittelpunkte bei der einen Theilung fallen mit den Würfelecken bei der anderen zusammen und vice versa.

Die dreizähligen Axen, welche in dem ersten Würfelsystem gezogen waren, durchschneiden Wurfelstränge des zweiten Systems gerade so wie diejenigen der ersten, und wenn wir, wie vorher, die Würfel durch die Buchstaben $\alpha, \beta, \gamma, \delta$ unterscheiden, je nach der Richtung, in welcher sie von einer dreizähligen Drehaxe durchschnitten werden, so werden Würfel, welche von der gleichen Axe durchkreuzt werden, immer durch den gleichen Buchstaben gekennzeichnet sein, und die Wurfelschicht des zweiten Systems, welche unmittelbar uber den Mittelpunk ten einer in Fig. 2 dargestellten Schicht liegen, wird, wie man findet, von diesen Drehaxen so durcbkreuzt wie Fig. 6 zeigt, und die Schicht, welche unmittelbar uber den Centren einer in Fig. 3 dargestellten Schicht liegt, so wie Fig. 7 zeigt.

Die Schraubenaxen des Typus 1, welche senkrecht auf den Zeichnungsebenen stehen, werden die Schichten des zweiten Würfelsystems in den in Fig. 6 und 7 mit $A, B, C, D$ bezeichnelen Punkten schneiden, und die Drehaxen des Typus 2 werden dieselben Schichten in den Punkten $E, F, G, H$ lreffen; die Durchschnittspunkle jeder Axe mit den vier Schichten sind so in jedem Falle gleich bezeichnet.

Um ein System vom Typus 3 aus einem System vom Typus 1 abzuleiten, können wir nun folgendermassen verfahren :

Um eine der zweizähligen Schraubenaxen des letzteren Systems, welche durch einen Punkt $B$ oder durch einén Punkt $C$ geht, führe man eine vierzäblige Rechtsschraubung **) aus, so dass zwei Bewegungen dieser Schraubung mit einer Bewegung der zweizähligen Schraubung äquivalent sind.

Da eine Drehung oder Schraubung um $90^{\circ}$ im Sinne des Uhrzeigers einen Wurfel $\alpha$ in einen Wurfel $\beta, \beta$ in $\gamma, \gamma$ in $\delta$ und $\delta$ in $\alpha$ verwandelt, so sehen wir aus der Betrachtung der Fig. 2, 3, 6 und 7, dass eine solche Schraubung die dreizähligen Drehaxen mit einander zur Deckung bringt, und folglich auch die verschiedenen zweizähligen Schraubenaxen zur Deckung bringt, deren Existenz ja, wie wir gesehen, durch Vorhandensein jener dreizähligen Axen bedingt ist.

*) Siehe S. 7.

**) Die Bewegung, welche ein Korkzieher macht, wenn er in einen Kork eindringt oder ihn verlässt, heisst eine Rechtsschraubung. 
Das Halbsystem der Würfel von dem ersten Würfelsysteme, welches die Triaden enthält, die ein System vom Typus 1 bestimmen, kommt mit einem Halbsysteme des zweiten Würfelsystems zur Deckung.

Die Triaden, welche ursprunglich in einem Halbsysteme des ersten Wurfelsystems vorhanden waren, finden sich daber jetzt in gleicher Weise angeordnet in einem Halbsysteme des zweiten Wurfelsystems. Die beiden so erhaltenen, identischen Punktsysteme haben die gleichen Axen, und das aus den beiden Systemen zusammengesetzte System besitzt also diese Axen ebenfalls.

Da ferner eine vierzahlige Rechtsschraubung um eine Axe durch einen Punkt $B$ das System, welches aus gleichen, durch andere Punkte $B$ gezogenen Axen besteht, zur Deckung bringt, so besitzt das zusammengesetzte System vierzählige Rechtsschraubungen um alle jene zweizähligen Axen der beiden Theilsysteme vom Typus 1, welche durch Punkte $B$ gehen. Und dies schliesst in sich gleiche vierzählige Schraubungen um die zweizähligen Axen durch $C$ und ebenso gleiche vierzählige Schraubungen um Axen, welche, in jeder der anderen beiden auf den Wurfelflächen senkrechten Richtungen, den beiden Schaaren von Axen durch $B$ und $C$ entsprechen.

Das zusammengesetzte System, welches aus der beschriebenen Ineinanderstellung zweier Systeme vom Typus 1 hervorgeht, ist ein Beispiel zum Typus 3 (65 nach Sohncke).

Seine Identität mit dem genannten Punktsysteme ist durch die Thatsache erwiesen, dass die relative Lage seiner oben beschriebenen Axen und Deckbewegungen die gleiche ist, wie jene der Axen und Deckbewegungen des letzteren Systems.

Um diese Identität besser veranschaulichen zu können, ist eine Copie von Sohncke's Figur des Systems 65 beigefügt (Fig. 8), in welcher die Projectionen der Würfelflächen als punktirte Linien angegeben sind. Die punktirten Linien sind verschieden fur die zwei verschiedenen Theilungen, und die Schnittpunkte der Axen sind der Bezeichnung in Fig. 2, 3, 6 und 7 entsprechend benannt.

Ein System vom Typus 4 (66 nach Sohncke) kann aus einem Systeme vom Typus 1 in äbnlicher Weise hergeleitet werden, wenn eine der zweizähligen Axen durch einen Punkt $A$ oder $D$ an Stelle einer solchen durch einen Punkt $B$ oder $C$ als vierzählige Schraubenaxe gewählt wird, und wenn die Schraubung eine linke statt einer rechten ist. Der Beweis wird mit dem oben gegebenen identisch sein.

Wir wollen nun weiter zeigen, dass ein System, welches ein Beispiel zum Typus 5 (62 nach Sohncke) ist, als das Ergebniss der Ineinanderslellung von vier mit einander identischen Systemen vom Typus 1 (58 nach Sohncke) angesehen werden kann, indem die Axen und Deckbewegungen 
dér vier Theilsysteme coincidiren und folglich auch dem zusammengesetzten Systeme zukommen.

Um ein System vom Typus b̆ aus einem Systeme vom Typus 1 abzuleiten, fưhrt man eine zweizählige Drehung aus, wie sie vorher angewandt wurde, um ein System vom Typus $2^{*}$ ) zu erzeugen, und ferner eine vierzählige Schraubung, wie sie eben ausgeführt wurde, um ein System vom Typus $3^{*}$ ) herzustellen. Die Ordnung, in welcher Drehung und Schraubung ausgeftuhrt werden, ist gleichgultig.

Oder anstatt der vierzähligen, zur Erzeugung des Typus 3 angewendeten Schraubung kann man die vierzählige Schraubung benutzen, die den Typus 4 erzeugt.

Die Ausfubrung beider Bewegungen, welche Schraubung wir auch anwenden mögen, bewirkt Deckung der dreizähligen Drehaxen, und folglich auch Deckung der verschiedenen Axen, deren Vorhandensein durch die Existenz jener dreizäbligen Axen bedingt ist, mit resp. Axen der gleichen Art.

Das Doppelsystem, gebildet aus den beiden Wurfelsystemen, in welche der Raum nach einander getheilt wurde, wird auch als Ganzes zur Deckung gebracht, aber das Halbsystem der Wurfel, die von Anfang an die ein System vom Typus 1 bestimmenden Triaden enthielten, wird direct oder indirect nach einander mit jedem der drei anderen Halbsysteme zur Deckung kommen.

Die Triaden, welche ursprunglich in einem bestimmten Halbsysteme der Wüfel vorhanden waren, werden durch eine der genannten Bewegungen in ein anderes der vier Halbsysteme gebracht, und dann kommt durch die zweite Bewegung das aus den zwei so gelegenen Systemen vom Typus 1 zusammengesetzte System an Stelle der ubrigen zwei der vier Halbsysteme von Wurfeln.

So kommt es, dass jedes der vier Halbsysteme von Wurfeln das System vom Typus 1 in den dasselbe bildenden Würfeln gleichartig angeordnet besitzt. Und da die erwăhnten Bewegungen die dreizähligen Axen zur Deckung bringen, so besitzen alle vier so gelegenen, identischen Punktsysteme dieselben Axen und Deckbewegungen, und das aus diesen vier Systemen zusammengesetzte System hat daber diese Axen und Deckbewegungen ebenfalls. Ausserdem besitzt es noch zweizählige Drehungen um Axen senkrecht zur Zeichnungsebene der Fig. 2, 3, 6 und 7, wie sie im Typus 2 vorhanden sind und vierzählige Rechtsschraubungen um jene der zwei Arten von Schraubenaxen vom Typus 1, welche im Typus 3 vierzählige Schraubenaxen geworden sind, und vierzäblige Linksschraubungen um die:

*) Siehe S. 10.

**) Siehe S. 11 . 
ubrigen zweizähligen Schraubenaxen vom Typus 1, welche vierzählige Schraubenaxen im Typus 4 geworden sind. Es besitzt auch Schaaren gleicher Deckbewegungen um entsprechende Axen, die in den beiden anderen, auf den Würfelflächen senkrechten Richtungen liegen.

Dieses zusammengesetzte System, welches in der beschriebenen Weise aus der Ineinanderstellung von vier Systemen des Typus 1 hervorgebt, ist ein Beispiel zum Typus 5 (62 nach Sohncke).

Seine Identitäl mit einem Punktsysteme des genannten Typus wird durch die Thatsache erwiesen, dass die relative Lage der entsprechenden Schrauben- und Drehaxen in beiden die gleiche ist.

Um diese Identität noch deutlicher hervortreten zu lassen, ist eine Copie von Sohncke's Figur des Systems 62 beigefügt (Fig. 9), in welcher die Projectionen der Wüfelflächen als punklirte Linien von zweierlei Art zu sehen sind, und die Schnittpunkte der Axen entsprechend wie in Fig. 2, 3,6 und 7 benannt sind.

Wir wollen nun dazu ubergehen zu zeigen, dass ein System, welches ein Beispiel zu Typus 6 ( 55 nach Sohncke) ist, als das Erzeugniss der Ineinanderstellung von vier mit einander identischen Systemen des Typus 1 (58 nach Sohncke) angesehen werden kann, indem die Axen und Deckbewegungen der sämmllichen vier Systeme dem zusammengesetzten Systeme ${ }^{*}$ ) angehören.

Um ein System vom Typus 6 aus einem Systeme des Typus 1 abzuleiten, können wir wie folgt vorgehen:

In einem beliebigen Wurfel eines der beiden vollständigen Wurfelsysteme, in welche der haum wie oben**) nach einander getheilt wurde, mache man ausser der Diagonale dieses Wurfels, welcher im Falle des Typus 1 bereits eine dreizählige Axe ist, irgend eine der drei übrigen Diagonalen auch zu einer dreizähligen Axe. Zieht man diese Linie, so bildet sie die gemeinschaftliche Diagonale eines Würfelstranges in jedem der beiden vollständigen Würfelsysteme, und durchläuft Würfel, welehe jedem der vier Halbsysteme von Wurfeln angehören. Und in jedem Würfel der beiden Systeme, welchen sie durchkreuzt, wird sie die in demselben schon vorhandene, dem Typus 1 angehörige dreizählige Axe im Würfelmittelpunkte schneiden.

Man fuhre nun dreizählige Drehungen aus um die dreizäbligen Axen des Typus 1 und ebenso um die vorhin neu hinzugekommene Axe, so dass alle neuen dreizähligen Axen, welche durch die Existenz dieser neuen Axe bedingt sind, dadurch erbalten werden.

*) Die Theilsysteme haben diesmal nicht wie in den vorhergehenden Fällen zusammenfallende Axensysteme.

**) Siehe S. 7 und 11 . 
Mapa wird finden, dass das so erhaltene, erweiterte System von Axen aus allen Linien besteht, welche gemeinschaftliche Diagonalen von Wurfelreiben der zwei vollständigen Systeme von Wurfeln bilden, in welche der Raum getheilt wurde. Jeder Wurfelmittelpunkt beider Systeme ist also der Schnittpunkt von vier dreizähligen Axen, welche die vier Wurfeldiagonalen sind.

Denn wo ein Würfel von der neuen Axe sowobl als von der zum Typus 1 gebörigen Axe durchkreuzt wird, ergiebt die Ausführung der dreizähligen Drehung um eine dieser zwei Axen zwei weitere Axen und verwandelt damit alle vier Würfeldiagonalen in dreizäblige Axen. Und weil die neue Axe Würfel eines jeden der vier Halbsystemen von Würfeln durchläuft, so ist dies in einigen Wurfeln eines jeden der vier Halbsysteme. der Fall.

Auf einander folgende dreizählige Drehungen des Typus 1 können aber einen Würfel mit einem beliebigen anderen Würfel desselben Halbsystems zur Deckung bringen*). Da also in einigen Wurfeln jedes der vier Halbsysteme von Wurfeln die vier Diagonalen dreizăblige Axen sind, so folgt daraus, dass sie es in jedem Würfel eines jeden dieser vier Halbsysteme sind.

Man sieht leicht, dass keine anderen dreizähligen Axen ausser diesen erhalten werden; denn, es ist klar, dass die Ausführung einer dreizähligen Drehung um irgend eine derselben die beiden ganzen Würfelsysteme zur Deckung bringt und deshalb immer die gemeinschaftliche Diagonale eines Wurfelstranges an die Stelle einer anderen solchen gemeinschaftlichen Diagonale bewegt und folglich keine dreizähligen Axen in anderer Lage als der der einen oder anderen der gemeinschafulichen Diagonalen im oben beschriebenen System ergeben wird.

Daher ist, wie oben festgestellt, das erweiterte System dreizäbliger Axen, welches sich ergiebt, wenn man eine Wurfeldiagonale, welche eine der dreizähligen Axen vom Typus 1 schneidet, zu einer neuen dreizähligen Axe macht, zugleich dasjenige System, welches entsteht, wenn alle Linien, welche gemeinschaftliche Diagonalen von aneinandergereihten Würfeln bilden, in welche der Raum getheilt worden, dreizählige Axen bilden.

Es wird nun gezeigl werden, dass die Folge dieser Erweiterung des Systems dreizähliger Axen in einem Punktsystem vom Typus 1 die Erzeugung eines Punktsystems des Typus 6 aus jenem ist.

Das eben abgeleitete erweiterte System von Axen ist erhalten worden, ohne die Existenz irgend welcher anderer als dreizähliger Axen vorauszusetzen; folglich werden alle neuen Lagen des Punktsystems vom Typus 1, welche aus der Erweiterung des Systems dreizähliger Axen folgen, solche

*) Siehe S. 8 . 
sein, dass man das Punktsystem in dieselben bringen kann, indem man Drehungen um eine oder mehrere dieser Axen ausfuhrt.

Nun bringt eine Drehung um irgend eine der dreizähligen Axen immer jedes der Halbsysteme von Wurfeln zur Deckung und bewirkt nicht das Zusammenfallen der neuen Lage des einen Halbsystems mit der ursprunglichen Lage eines anderen*). Welche aufeinder folgende Drehungen um diese Axen also auch ausgefuhrt werden mögen, immer werden die Triaden des Systems 1 noch in demselben Halbsystem zu finden sein, in welchem sie ursprunglich lagen.

Nun zu den Lagen, welche die Triaden in den Wurfeln dieses Halbsystems einnebmen!

Die Ecken der Würfel des Halbsystems können in zwei Classen getheilt werden; die eine Classe enthält vier der acht Ecken jedes Wurfels, welche verbunden reguläre gleich und gleichliegende Tetraëder bilden, die andere die übrigen vier, welche ebenfalls reguläre, gleiche und gleichliegende Tetraëder bilden, deren Orientirung jedoch derjenigen der von der ersten Classe gebildeten Tetraëder entgegengesetzt ist. Und es ist leicht zu sehen, dass keine Drehung um eine der dreizähligen Axen eine Ecke der einen dieser Classen mit einer Ecke der anderen Classe zur Deckung bringen wird.

Folglich werden durch die Ausführung aufeinander folgender Drehungen um die dreizähligen Axen des erweiterten Systems drei und nur drei neue Triaden, identisch mit der schon vorhandenen Triade des Typus 1, in jeden Wurfel des Halbsystems der Würfel, welche die Triaden vom Typus 1 enthalten, gebracht; diese neuen Triaden liegen so, dass die Deckbewegungen des Systems der durch die jetzt vorhandenen vier Triaden gebildeten 12 Punkte diejenigen eines regulären Tetraëders sind, dessen Ecken die Hälfte der Wüfelecken einnebmen. Mit anderen Worten: diese 12 Punkte bilden einen 12-Punkter von Sohncke**), dessen Mittelpunkt und Axen mit dem Mittelpunkt und den Axen des eben erwähnten Tetraëders ubereinstimmen.

Nun bilden die Mittelpunkte der Wüfel eines jeden der vier Halbsysteme der Würfel das, was Sohnck e »ein regulär oktaëdrisches Raumgitter (***) nennt, und daher besteht das Punktsystem, welches aus der oben beschriebenen Erweiterung des Systems dreizähliger Axen des Typus 1 entsteht, aus identischen 12-Punktern, deren Mittelpunkte ein regulär oktaëdrisches Raumgitter bilden, und deren Axen parallel zu den entsprechen-

*) Vergl. S. 8 .

**) Siebe Entwickelung einer Theorie etc. S. 156 bezüglich S ohncke's Definition eines "12-Punkters «.

***) Entwickelung etc. S. 157. 
den Axen dieses Raumgitters sind. Es ist daher ein Beispiel zu Sobncke's System 55*).

Um nun zu beweisen, dass das eben beschriebene System aus vier mit einander identischen Punktsystemen vom Typus 1 besteht, und dass es ibre Axen und Deckbewegungen besitzt, können wir folgendermassen vorgehen :

Zwei dreizählige Drehungen um zwei Diagonalen eines beliebigen Wurfels können so gewählt werden, dass ibre Resultante eine zweizählige Drehung um eine Axe ist, welche senkrecht auf einer der drei Ebenen des Würfels steht und durch den Mittelpunkt desselben geht**). Daher besitzt das erweiterte System drei Schaaren von Axen, welche je auf den drei Ebenen der Wurfel senkrecht stehen; drei dieser Axen, je eine aus einer Schaar, schneiden sich in jedem Würfelcentrum.

Durch den Mitlelpunkt eines der Würfel, welche eine Triade des Typus 1 enthalten, ziehe man drei solche Axen:

Man fübre eine zweizählige Drehung um eine derselben aus und bringe so eine zweite Triade in jeden Würfel des die Triaden des Typus 1 enthaltenden Halbsystems. Die Lage der Axen dieser zweiten Triaden können leicht in Fig. 2 und 3 aufgesucht werden: eine zweizählige Drehung um eine zur Zeichnungsebene senkrechte Axe verwandelt Würfel $\alpha$ in Würfel $\gamma$, $\beta$ in $\delta, \gamma$ in $\alpha$ und $\delta$ in $\beta$.

Auf das aus den zwei identischen Systemen des Typus 1 zusammengesetzte System, welches erhalten wird, wenn man sowohl die alte als die neue Lage der Triaden nimmt, wende man eine zweite zweizählige Drehung um eine andere der drei eben gezogenen Axen an.

Die Folge davon ist offenbar die, dass in jedem der Würfel, welche die Triaden enthalten, die zwei Diagonalen, um welche die Triaden gruppirt sind, an den Ort der beiden anderen Diagonalen gebracht werden, so dass man vier gleichartige Lagen für das System des Typus 1 erhält.

Die so erhaltenen vier identischen Systeme ergeben zusammengenommen offenbar das System des Typus 6.

Ferner, wenn man das erweiterte System dreizähliger Axen von jenen eines Systems vom Typus 1 herleitel; so werden die dreizähligen Drebungen des letzteren unverändert beibehalten, und daher besitzt dieses erweiterte System jene dreizähligen Drehungen und alle anderen durch die Existenz derselben bedingten Deckbewegungen. Und wegen der Symmetrie besitzt es auch die Deckbewegungen der drei anderen identischen Systeme des Typus 1, welche an seiner Zusammensetzung theilnehmen.

*) Siehe Entwickelung einer Theorie etc., S. 156 und 177.

**) Vergl. Kinematische Hülfsbetrachtung III (Euler'scher Satz), Entwickelung einer Theorie etc. S. 31. 
Es ist also festgestellt, dass ein System des Typus 6 aus vier identischen Systemen des Typus 1 besteht, welche in der bestimmten Weise in einander gestellt sind, wobei die Axen und Deckbewegungen dieser sämmtlichen vier Systeme dem zusammengesetzten System zukommen.

Wir wollen nun zum Beweise tabergehen, dass ein System, welches ein Beispiel zum Typus 7 ( 54 nach So h n cke) ist, als Ergebniss der Ineinanderstellung von acht mit einander identischen Punktsystemen des Typus 1 ( 58 nach Sohncke) betrachtet werden kann, wobei die Axen und Deckbewegungen dieser acht Theilsysteme auch dem zusammengesetzten System angehơren.

Um ein System vom Typus 7 aus einem System des Typus 1 abzuleiten, fuhre man eine zweizählige Drehung aus, so wie sie eben angewandt wurde, um ein System des Typus $2 *$ z) zu erzeugen und ferner zwei zweizählige Drehungen, wie sie gerade ausgefuhrt wurden, um ein System des Typus 6 zu erhalten; die Reihenfolge ist gleichgttlig.

Man sieht leicht, dass, wenn acht identische Systeme des Typus 1 in dieser Weise symmetrisch angeordnet werden, das sich ergebende zusammengesetzte System wie Typus 6 ein System von gleichen 12-Punklern ist. In diesem Falle jedoch enthalten alle Würfel eines der Systeme von Würfeln, in welche der Raum geteilt wurde ${ }^{* *}$ ), 12-Punkter und nicht bloss die Hälfte derselben wie im Falle des Typus 6. Die Mittelpunkte der 12Punkter bilden daher ein kubisches Raumgitter ***).

Das erweiterte System dreizäbliger Axẹn des Typus 6 gehört offenbar diesem System an, und da wir schon gesehen haben, dass dieses erweiterte System die Axen des Typus 1 umfasst, so ist der obige Satz aus Gründen der Symmetrie bewiesen.

Wir wollen nun fortfahren zu zeigen, dass ein System, welches ein Beispiel des Typus 8 ( 60 nach Sohncke) ist, als das Resultat der Ineinanderstellung von acht mit einander identischen System des Typus 1 (58 nach Sobncke) angesehen werden kann, wobei das zusammengeselzte System die Axen und Deckbewegungen dieser acht Theilsysteme besilzt.

Um ein System vom Typus 8 aus einem System des Typus 1 herzuleiten, fübre man zwei solche zweizählige Drehungen aus, wie sie zur Erzeugung eines Systems vom Typus 6 angewandt wurden, und sodann eine vierzählige Drehung, indem man die Axe einer dieser Drehungen in eine vierzählige verwandelt.

*) Siehe S. 10.

**) Dies gilt in gleicher Weise für die beiden Theilungen.

***) Siehe Entwickelung einer Theorie etc., S. 156. 
Man sieht leicht, dass die zwei Lagen des Systems von 12-Punktern des Typus 6, welche man durcb Anwendung der letzteren Drehung erhält, zusammengenommen ein System von 24-Punktern ergeben, deren Mittelpunkte und deren dreizählige Axen jene des Systems von 12-Punktern sind *).

Es wurde gezeigt, dass das System vom 12-Punktern aus vier Systemen des Typus 1 besteht und die Axen dieser Systeme besitzt; deshalb besteht das System von 24-Punktern aus acht solchen Systemen und besitzt ebenfalls ihre Axen.

Die obige Behauptung ist also bewiesen.

Wir wollen nun weitergehen und zeigen, dass ein System, welches ein Beispiel zum Typus 9 (63 nach Sohncke) ist, als das Ergebniss der Ineinanderstellung von acht mit einander identischen Systemen des Typus 1 (58 nach Sohncke) betrachtet werden kann, wobei das zusammengesetzte System die Axen und Deckbewegungen dieser acht Theilsysteme besitzt.

Um ein System des Typus 9 aus einem System des Typus 1 abzuleiten, fuhre man eine vierzählige Schraubung aus, entweder eine solche, wie sie gerade angewandt wurde, um ein System des Typus 3 zu erzeugen, oder die zur Erzeugung des Typus \& gebrauchte, und ferner zwei zweizählige Drehungen, wie sie zur Herstellung des Typus 6 nöthig waren**); die Aufeinanderfolge ist gleichgültig. Jede der obigen Schraubungen bringt das erweiterte System dreizähliger Axen zur Deckung.

Wenn die Drehungen zuerst ausgefuhrt werden, sieht man leicht, dass die zwei Lagen des Systems von 12-Punktern des Typus 6, welche man durch Anwendung einer der erwähnten Schraubungen erhält, 12-Punkter in den Wurfeln eines Halbsystems von Würfeln jeder der beiden Raumtheilungen ergeben; die 12-Punkter des einen Halbsystems haben jedoch die entgegengesetzte Orientirung bezüglich der vier Richtungen der Wurfeldiagonalen, wie jene der 12-Punkter des anderen Halbsystems.

Das in dieser Weise aus acht identischen Systemen vom Typus 1 zusammengesetzte System hat, weil es das erweiterte System der dioizăhligen Axen besitzt, die Deckbewegungen dieser Axen, welche, wie wir gesehen, die Deckbewegungen des Typus 1 in sich begreifen.

Die Identität dieses zusammengesetzten Systems mit Sohncke's System 63 wird durch die Thatsache bewiesen, dass die relative Lage entsprechender Schrauben- und Drehaxen in beiden die gleiche ist.

Um diese Identität besser hervortrelen $z u$ lassen, ist eine Zeichnung beigefügt (Fig. 10), welche die relativen Lagen entsprechender Gruppen

*) Vergl. Entwickelung einer Theorie etc., S. 166.

**) Siehe S. 11, 12, 17 . 
von vier Punkten jedes 12-Punkters vielleicht etwas deutlicber zeigt als Fig. 63, Taf. V in Sohncke's Werk, welche dieselbe Art Theilsystem darstellt. Die Bezeichnungsweise entspricht der in den Fig. 2, 3, 6 und 7.

Wir wollen nun weiter zeigen, dass ein System, welches ein Beispiel zu Typus 10 (56 nach Sohncke) ist, als das Resultat der Ineinanderstellung von sechzehn mit einander identischen Systemen des Typus 1 (58 nach Sobncke) angesehen werden kann, wobei die Axen und Deckbewegungen dieser 16 Theilsysteme dem zusammengesetzten Systeme angehören.

Um ein System des Typus 10 aus einem Systeme des Typus 1 abzuleiten, führe man in beliebiger Ordnung aus: eine zweizăhlige Drehung, wie sie eben angewandt wurde, um ein System des Typus $2^{*}$ ) zu erhalten, zwei zweizählige Drebungen, wie sie zur Erzeugung eines Systems vom Typus $\left.6^{* *}\right)$ nöthig waren, und eine Schiebung in einer der vier Richtungen der Würfeldiagonalen, so dass die Wurfel, ị welche der Raum durch die erste Theilung eingetbeilt wurde, zur Deckung mit jenen kommen, in welche der Raum durch die zweite Theilung abgetheilt ward.

Wenn die Drehungen zuerst ausgefuhrt werden, sieht man leicht, dass die zwei Lagen des Systems von 12-Punktern des Typus 7, welche man durch die Ausführung der Schiebung erhält, identische 12-Punkter in allen Würfeln der beiden Systeme von Würfeln ergeben, in welche der Raum nach einander getheilt wurde; und dass das erbaltene zusammengesetzte System aus 16 identischen Systemen des Typus 1 bosteht. Ueberdies bringt diese Schiebung das erweiterte System der dreizähligen Axen zur Deckung, und daher besilzt das zusammengesetzle System die Deckbewegungen dieser Axen, welche die Deckbewegungen des Typus $\uparrow$ in sich begreifen.

Die Identităt dieses zusammengesetzten Systems mit Sohncke's System 56 wird durch die Thatsache bewiesen, dass die relative Lage der entsprechenden Schrauben- und Drehaxen und Schiebungsrichtungen in beiden dieselbe ist.

Es soll nun weiter gezeigt werden, dass ein System, welches ein Beispiel zu Typus 11 (64 nach Sohncke) ist, als das Product der zusammensetzung von sechszehn mit einander identischen Systemen des Typus 1 (58 nach Sohncke) betrachtet werden kann, jndem die Axen und Deckbewegungen dieser 16 Theilsysteme dem zusammengesetzten Systeme zukommen.

Um ein System des Typus 11 aus einem Systeme des Typus 1 abzuleilen, fụhre man in beliebiger Ordnung aus: eine zweizählige Drehung,

*) Siehe S. 10.

**) Siehe S. 17 . 
wie sie vorhin angewendet wurde, um ein System des Typus 2 zu erzeugen, eine vierzählige Schraubung, entweder eine solche, wie sie zur Herstellung eines Systems des Typus 3 nöthig war, oder die zur Erzeugung eines Systems vom Typus 4 gebraucbte, und zwei zweizähligen Drehungen, wie sie die Erzeugung eines Systems des Typus 6 verlangte.

Man sieht leicht, wenn die zur Erzeugung des Typus 6 erforderlichen zweizähligen Drehungen zuerst ausgeftihrt werden, dass die vier Lagen von 12-Punktern des Typus 6, welche man durch die Ausführung der ubrigen Bewegungen erhält, gleiche 12-Punkter in die Würfel aller vier Halbsysteme von Wurfeln liefern, in welche der Raum getheilt worden, wobei jedoch die 12-Punkter des einen vollständigen Würfelsystems die ontgegengesetzte Orientirung beztglich der vier Richtungen der Wurfeldiagonalen haben, wie jene des anderen vollständigen Wurfelsystems.

Das derartig aus sechzebn identischen Systemen des Typus 1 aufgebaute System hat, da es das erweiterte System dreizähliger Axen besitzt, die Deckbewegungen dieser Axen, welche jene des Typus 1 in sich begreifen.

Die Identität dieses zusammengesetzten Systems mit S obncke's System 64 wird durch die Thatsacbe bewiesen, dass die relative Lage der entsprechenden Scbrauben- und Drebaxen in beiden dieselbe ist.

Um diese Identität besser hervortreten zu lassen, ist eine Zeichnung beigefugt (Fig. 11), welche die relativen Lagen entsprechender Gruppen von vier Punkten jedes 12-Punkters vielleicht etwas deutlicher zeigt, als Fig. 64, Tafel $\mathrm{V}$ in Sohncke's Werk, welche dieselbe Art Theilsystem darstellt. Die Bezeichnungsweise entspricht der in den Fig. 2, 3, 6 und 7.

Wir wollen nun weiler zeigen, dass ein System, welches ein Beispiel zu Typus 12 (59 nach Sohncke) ist, als das Resultat der Zusammensetzung von 16 mit einander identischen Systemen des Typus 1 (58 nach Sohncke) angesehen werden kann, indem die Axen- und Deckbewegungen dieser 16 Theilsysteme dem zusammengesetzten Systeme angehören.

Um ein System des Typus 12 aus einem Systeme des Typus 1 abzuleiten, führe man in beliebiger Ordnung aus: eine zweizählige Drehung, wie sie gerade angewendet wurde, um ein System des Typus 2 zu erzeugen, zwei zweizählige Drehungen, wie sie zur Erzeugung eines Systems des Typus 6 erforderlich waren, und ferner eine vierzählige Drehung, indem man die Axe einer dieser letztgenannten Drehungen in eine vierzählige Axe verwandelt.

Man sieht leicht, dass die zwei Lagen des Systems von 12-Punktern des Typus 7, welche man durch die Ausführung der letztgenannten Drehung erhält, zusammengenommen ein System von 24-Punktern erzeugen, deren 
Gentra und deren dreizählige Axen diejenigen des Systems von 12-Punktern sind.

Es wurde gezeigt, dass das System von 12-Punktern aus acht Systemen des Typus 1 besteht und die Axen dieser Systeme besitzt; das System der 24-Punkter besteht also aus 16 solchen Systemen und besitzt ebenfalls ihre Axen.

Es soll nun weiter gezeigt werden, dass ein System, welches ein Beispiel zu Typus 13 (61 nach Sohncke) íst, als das Resultat der Ineinanderstellung von 32 mit einander identischen Systemen des Typus 1 (58 nach Sohncke) betrachtet werden kann, indem das zusammengesetzte System die Axen und Deckbewegungen dieser 32 Theilsysteme besitzt.

Um ein System des Typus 13 aus einem System des Typus 1 abzuleiten, fuhre man in beliebiger Ordnung aus: eine zweizählige Drehung, wie sie angewendet wurde, um ein System des Typus 2 zu erbalten; eine vierzählige Schraubung, entweder, eine solche, welche zur Herstellung eines Systems des Typus 3 nöthig war, oder die zur Erzeugung eines Systems des Typus 4 erforderliche, zwei zweizählige Drehungen, wie sie die Erzeugung eines Systems des Typus 6 verlangte, und endlich eine vierzählige Drehung, indem man die Axe einer dieser beiden letztgenannten Drehungen in eine vierzählige Axe verwandelt.

Man sieht leicht, dass die zwei Lagen des Systems von 12-Punktern des Typus 11, welche man durch die letztere Drehung erhält, zusammengenommen ein System von 24-Punktern ergeben, deren Centra und deren dreizäblige Axen jene des Systems der 12-Punkter sind.

Es wurde gezeigt, dass das System der 12-Punkter aus sechzehn Systemen des Typus 1 besteht und die Axen dieser Systeme besitzt; daher besteht das System der 24-Punkter aus 32 solchen Systemen und besitzt ihre Axen ebenfalls.

Entsprechend jedem der so untersuchten 13 regelmässigen Sohnckeschen Systeme giebt es einen mindest-symmetrischen Typus einer homogenen Structur ohne Symmetriecentren und Symmetrieebenen, welcher dieselben Deckbewegungen wie das Sohncke'sche System besitzt, und in welchem daher jede Schaar gleichartiger Punkte ein solches Punktsystem bestimmt.

Von diesen 13 Typen der homogenen Structur baben jene fünf, deren Punktsysteme beziehungsweise den Typen 1, 2, 6, 7 und 10 angehören, die 'Tetartoëdrie der Classe 32 in Sohncke's Verzeichniss der Krystallclassen*), und die ubrigen acht, deren Punktsysleme bezw. von den Typen 3 , $4,5,8,9,11$ und 13 sind, die gyroëdriscbe Hemiëdrie der Classe 29. Alle

*) Diese Zeitschr. 20, 467. 
13 Typen homogener Structur haben denselben Grad der Symmetrie, wie die mindest-symmetrischen Punktsysteme, welche ihre gleichartigen Punkte bestimmen.

\section{Die hexagonale Systemgruppe.}

Diese Rubrik umfasst nur jene Systeme, welche sechszählige Axen besitzen.

Die zwölf Sobncke'schen Systeme, welche hexagonale Symmetrie besitzen, d. s. jene unter V A, V B seiner Uebersichtstabelle, bestehen je aus einer endlichen Anzahl mit einander identischer Systeme, entweder von dem Muster, welches Sohncke als System 42 bezeichnet, oder von dem als 43 bezeichneten, und jedes der zwölf Systeme besitzt die Axen und Deckbewegungen der Systeme, aus welchen es gebildet wird.

Genauer :

Typus 14 und $15=$ S ohncke's Systemen 42 und 43.

Typus 16 und 17 (System 44 und 45) entstehen durch die Ineinanderstellung zweier mil einander identischer Systeme bezw. vom Typus 14 und 15; die Axen und Deckbewegungen dieser Theilsysteme gehören auch dem zusammengesetzten Systeme an.

Typus 18 und 19 (System 48 und 49 ) bestehen ebenfalls bezüglich aus zwei solchen Systemen, die ebenso mit dem zusammengesetzten Systeme in Beziehung slehen.

Typus 20 (System 46) besteht aus drei mit einander identischen Systemen entweder vom Typus 14 oder vom Typus 15.

Typus 21 und 22 (System 50 und 51) bestehen aus vier mit einander identischen Systemen bezw. vom Typus 14 und Typus 15.

Typus 23 (System 47) besteht aus sechs solchen Systemen des Typus 14 oder des Typus 15.

Typus 24 (System 52) besteht ebenfalls aus sechs solchen Systemen vom Typus 14 oder 15.

Typus 25 (System 53) besteht aus zwölf solchen Systemen vom Typus 14 oder vom Typus 15.

Diese Sätze können in fast derselben Weise bewiesen werden, wie jene bezüglich der regulären Systemgruppen.

Um die Typen 14 oder 15 ( 42 und 43 nach Sohncke) zu erhalten, theile man den Raum in gleiche regelmässige secbsseitige Prismen mit ebenen Endflächen, welche zusammenhängende Ebenen bilden.

Man nehme nun irgendwo einen Punkt in dem Systeme der Prismen an und lege durch denselben eine Ebene senkr'echt zu den Prismenaxen. Durch geeignete Schiebungen bringe man entsprechende Punkte in jedes der regelmässigen Sechsecke, in welche diese Ebene durch die Prismenfächen getheilt wird. Schliesslich fübre man eine Reihe sechszäbliger 
Schraubungen um eine beliebige Prismenaxe aus; die Schiebungscomponente dieser Schraubungen ist die Länge eines Prismas. In Folge dieser Schraubungen gelangt ein entsprechender Punkt in jedes der hexagonalen Prismen, welche den Raum erfullen.

Das so erhaltene Punktsystem wird offenbar ein Beispiel zu Typus 14 oder zu Typus 15 sein, je nachdem die angewandte Schraubung eine rechte oder eine linke ist *).

Die Typen 16 und 17 ( 44 und 45 nach Sohncke) entstehen bezw. aus den Typen 14 und 15 , welche als Theilsystem angewandt werden, wenn aus 14, bezw. 15 zwei identische Systeme hergestellt werden mittels einer zweizähligen Drehung um eine Axe, welche mit einer Prismenaxe zusammenfällt, oder um eine zu dieser parallelen Axe, welche in der Mitte zwischen zwei nächsten Prismenaxen liegt.

Die Typen 18 und 19 ( 48 und 49 nach Sohn oke) entstehen bezuglich aus den Typen 14 und 15, welche als Theilsystem angewendet werden, wenn aus 14 bezw. 15 zwei identische Systeme erzeugt werden mittels einer zweizähligen Drehung, welche das System der Prismenaxen zur Deckung bringt, während die Richtung dieser Axen umgekehrt wird.

Dies wird der Fall sein, wenn die zweizahlige Axe senkrecht zur Prismenaxe durch zwei gegenuberliegende Prismenkanten oder senkrecht zu zwei gegenuberliegenden Prismenflächen geht. Das durch eine solche Drehung erhaltene, den Raum erfüllende Doppelsystem von Prismen besitzt offenbar die Deckungen der Typen 14 und 15.

Typus 20 ( 46 nach S oh ncke) entsteht aus Typus 14 oder Typus 15 , als Theilsystem angewendet, wenn drei identische Systeme des einen dieser Typen hergestellt werden durch zwei aufeinanderfolgende dreizählige Drehungen um eine Axe, welche mit einer der sechszähligen Axen des Theilsystems zusammenfällt, oder um eine Axe, welche parallel zu dieser in der Mitte dreier nächster sechszähliger Axen verläuft.

Die Typen 21 und 22 ( 50 und 51 nach Sohncke) entstehen bezuglich aus Typus 14 oder 15 , als Theilsystem angewendet, wenn vier identische Systeme des geeigneten der beiden genannten Typen hergestellt werden durch aufeinanderfolgende Ausfübrung der zur Erzeugung der Typen 16 und 17 nöthigen zweizähligen Drehung und der zur Herstellung der Typen 18 und 19 erforderlichen zweizäbligen Drehung.

Typus 23 (47 nach Sohncke) entstehl aus Typus 14 oder 15 , als Theilsystem angewendet, wenn sechs identische Systeme eines dieser Typen

*) Es ist klar, dass erzeugende Punkte, welche in derselben Parallelen zur Prismenaxe liegen, alle identische Punktsysteme hervorbringen werden, wenn Schraubungen von der gleichen Windung angewandt werden. 
hergestellt werden mittels auf einander folgender sechszähliger Drehungen um eine Axe, die mit einer der sechszähligen Axen des Theilsystems zusammenfällt.

Typus 24 (52 nach Sohncke) entsteht aus Typus 14 oder 15 , als Theilsystem angewandt, wenn man mittels der zur Erzeugung des Typus 20 nöthigen dreizäbligen Drehungen und der zur Entstehung der Typen 18 und 19 erforderlichen zweizäbligen Drebung secbs identische Systeme des einen der beiden Typen herstellt.

Typus 25 (53 nach Sohncke) entsteht aus Typus 14 oder 15 , als Theilsystem angewendet, wenn man nacheinander ausfuhrt: die zur Herstellung des Typus 18 und 19 nötbige zweizäblige Drehung und die zur Erzeugung des Typus 23 gebrauchte sechszählige Drehung. Dadurch werden 12 identische Systeme eines dieser Typen ineinander gestellt.

Jedem der 12 So h ncke'schen Systeme der hexagonalen Gruppe entsprechend, giebt es einen mindest-symmetrischen Typus homogener Structur ohne Symmetriecentren und Symmelrieebenen, welcher die gleichen Deckbewegungen wie das Sobncke'sche Punktsystem besitzt und in welchem daher jede Schaar homologer Punkte ein derartigès Punktsystem vorstellt.

Von diesen 12 Typen homogener Structur haben je sechs, deren Punktsysteme von den Typen 14, 15, 16, 17, 20 und 23 sind, die pyramidale Hemimorphie der Classe 18 in Sohncke's Verzeichniss der Krystallclassen *), und die tubrigen sechs, deren Punktsysteme den Typen 18, 19, 21, 22, 24 und 25 angehören, die trapezoëdrische Hemiëdrie der Classe 10.

Es mag bemerkt werden, dass die Punkisysteme der 'Typen 20 und 23 ( 46 und 47 nach Sohncke), fur sich betrachtet, eine höhere Symmetrie besitzen, als die oben erwähnten mindest-symmetrischen homogenen Structuren, welche dieselben enthalten; sie besitzen Symmetrieebenen, welche die Punktebenen schneiden und baben die Symmelrie der Classe 11 in Sohn cke's Verzeichniss.

\section{Die tetragonale Systemgruppe.}

Die 16 Sohncke'schen Systeme, welche tetragonale Symmetrie besitzen, $d$. s. jene unter IV A und IV B seiner Uebersichtstabelle, bestehen je aus einer endlichen Anzahl mit einander identischer Systeme entweder von dem Muster, welches von Sohncke als System 26 bezeichnet wird, oder von jenem als System 27 bezeichneten, und jedes der 16 Systeme besitzt die Axen und Deckbewegungen der Systeme, aus welchen es aufgebaut ist.

Genauer:

Die Typen 26 und $27=$ System 26 und 27 von Sobncke.

*) Siebe diese Zeitschr. 20, 463. 
Typus 28 (System 28) entsteht durch die Ineinanderstellung zweier mit einander identischer Systeme entweder des Typus 26 oder des Typus 27; die Axen und Deckbewegungen der Theilsysteme gehören überdies in jedem Falle dem zusammengesetzten System an.

Typus 29 (System 29) besteht ebenfalls aus zwei solchen Systemen einer der Typen, welche mit dem zusammengesetzten System in derselben Beziehung stehen.

Typus 30 und 31 (System 32 und 33) bestehen aus zwei solchen Systemen bezw. vom Muster der Typen 26 und 27.

Typus 32 und 33 (System 38 und 39) bestehen ebenso bezw. aus zwei identischen Systemen dieser selben beiden Systeme.

Typus 34 (System 30) besteht aus vier identischen Systemen eines der zwei Typen.

Typus 35 (System 34) besteht gleichfalls aus vier solchen identischen Systemen.

Typus 36 (System 35) besteht auch aus vier.

Typus 37 (System 40) ebenfalls aus vier.

Typus 38 (System 31) ist aus acht solchen identischen Systemen zusammengesetzt.

Typus 39 (System 36) desgleichen aus acht.

Typus 40 (System 41) desgleichen aus acht.

Typus 41 (System 37) besleht aus 16 solchen identischen Systemen.

Wie schon gesagt, sind in jedem Falle die Axen und Deckbewegungen aller identischer Theilsysteme dem zusammengesetzten System eigenthumlich.

Diese Sälze können in fast gleicher Weise bewiesen werden, wie jene für die regulären Systemgruppen.

Um die Typen 26 und 27 (26 und 27 nach Sohncke) zu erhalten, theile man den Raum in gleiche quadratische Prismen durch die Schaaren paralleler Ebenen, welche gegenseitig auf einander senkrecht stehen. Die Prismenaxen können nun als vierzählige Schraubenaxen betrachtet werden, deren Schiebungscomponente ein ganzes Vielfaches der Prismenlänge ist.

Man nehme nun irgendwo in dem Prismensystem einen Punkt an und lege durch denselben eine Ebene parallel zu den Endflächen der Prismen. Durch geeignete Schiebungen bringe man entsprechende Punkte symmetrisch in die Halfte der Quadrate des Quadratsystems, in welches diese Ebene durch die Prismenflächen getheilt wird, und schliesslich fuhre man eine Reihenfolge von Bewegungen der vierzähligen Schraubung aus um eine der erwähnten vierzahligen Axen, indem man die Schiebungscomponente gleich der doppelten Prismenlänge macht.

Die Folge ist die Erzeagung entsprechender Punkte in einem von je vier der den Raum erfüllenden Prismen. 
Das so erhaltene Punktsystem wird offenbar ein Beispiel zu Typus 26 oder zu Typus 27 sein, je nachdem die angewandte Schraubung eine rechte oder linke ist.

Typus 28 (28 nach Sohncke) entsteht entweder aus Typus 26 oder aus Typus 27, als Theilsystem angewandt, wenn zwei identische Systeme eines dieser Typen hergestellt werden mittels einer zweizähligen Drehung um eine zu den Prismenaxen parallele Axe, so dass das Viertelsystem der Prismen, welches die Punkte eines Theilsystems enthält, mit dem transversal (seitlich) angrenzenden Viertelsystem zur Deckung gebracht wird.

Eine solche Axe wird die Mittellinie einer Prismenfläche sein, welche parallel zu den Prismenkanten läuft.

In dem so erhaltenen, zusammengesetzten System werden die Prismenkanten vierzählige Schraubenaxen.

Typus 29 (29 nach Sohncke) entsteht entweder aus Typus 26 oder Typus 27, als Theilsystem angewendet, wenn man mit Hülfe einer zweizäbligen Drehung um eine der Prismenaxen zwei identische Systeme eines dieser Typen herstellt. Es fallen jetzt zwei Punkte in jedes Prisma des Viertelsystems der Prismen, welche die Punkte enthalten.

Die Typen 30 und 31 (32 und 33 nach S ohn cke) werden beziehungsweise aus den Typen 26 und 27, als Theilsystem angewandt, abgeleitet, wenn zwei identische Systeme von dem geeigneten Typus der beiden zuletzt genannten hergestellt werden mittels einer zweizähligen Drehung um eine Axe, deren Richtung senkrecht zur Richtung der Prismenaxen steht, und welche so liegt, dass die Ausfubrung der Drehung die Axen der Prismen, welche die Punkte des Theilsystems enthalten, zur Deckung bringt, wobei jedoch die Richtung dieser Axen die entgegengesetzte wird.

Zu diesem Zweck muss die Axe der zweizähligen Drehung durch zwei gegenuberliegende Kanten eines Prismas gehen oder durch Parallele zu diesen, welche die Mittellinien zweier gegenüberliegender Prismenflächen bilden.

Das Doppelsystem der den Raum erfüllenden Prismen besilzl offenbar die Axen und Deckbewegungen der Typen 26 und 27.

Die Typen 32 und 33 ( 38 und 39 nach S ohn cke) entstehen bezüglich aus den Typen 26 und $2 \%$, als Theilsystem angewandt, wenn man zwei identische Systeme vom betreffenden der genannten Typen herstellt mit Hulfe einer zweizähligen Drehung um eine Axe, deren Richtung senkrecht zur Richtung der Prismenaxen ist, und welche so liegt, dass die Ausfübrung der Drehung die Axen der Prismen, welche die Punkte des Theilsystems enthalten, in die Lagen bringt, welche ursprunglich die Axen jener Prismen einnahmen, welche seitlich an dieselben stossen, wobei jedoch die Richtung der Axen die entgegengesetzte wird. 
Zu diesem Zweck muss die Axe der zweizähligen Drehung in einer Prismenfläche liegen.

Wie vorher besitzt das Doppelsystem der den Raum erfullenden Prismen offenbar die Axen und Deckbewegungen der Typen 26 und 27.

Typus 34 (30 nach Sohncke) entsteht aus Typus 26 oder 27, als Theilsystem angewendet, wenn vier identische Systeme des einen oder anderen dieser Typen hergestellt werden mittels aufeinanderfolgender vierzähliger Drehungen um eine Axe, welche mit einer der Prismenaxen, d. h. mit einer Axe von irgend einer Art der vierzähligen Schraubungen des Theilsystems zusammenfällt.

Typus 35 (34 nach Sohncke) wird entweder aus Typus 26 oder aus 'Typus 27, als Theilsystem gebraucht, erzeugt, wenn vier identische Systeme. eines dieser Typen hergestellt werden durch die aufeinanderfolgende Ausführung der zur Erzeugung des Typus 28 angewendeten zweizähligen Drehung und entweder der zur Herstellung der Typen 30 und 31 nölhigen zweizähligen Drehung oder der zur Erzeugung der Typen 32 und 33 gebrauchten zweizähligen Drehung.

Typus 36 (35 nach Sohncke) erhält man entweder aus Typus 26 oder aus Typus $2 \%$, als Theilsystem angewendet, wenn vier identische Systeme eines dieser Typen hergestellt werden durch die aufeinanderfolgende Ausfuhrung der zur Erzeugung des Typus 29 angewandten zweizähligen Drehung und der zur Entstehung der Typen 30 und 31 nöthigen zweizähligen Drehung.

Typus 37 (40 nach Sohncke) entsleht enlweder aus Typus 26 oder aus Typus 27, als Theilsystem angewandt, wenn vier identische Systeme des einen oder anderen dieser Typen hergestellt werden durch die successive Ausführung der zur Erzeugung des Typus 29 nöthigen zweizähligen Drehung und der zur Bildung der Typen 32 und 33 gebrauchten zweizähligen Drehung.

Typus 38 ( 31 nach Sohncke) entsteht entweder aus Typus 26 oder aus Typus 27, als Theilsystem gebraucht, wenn man acht identische Systeme eines dieser Typen dadurch herstellt, dass man nacheinander ausfuhrt: die vierzähligen Drehungen, welche gebraucht wurden, um Typus 34 zu erzeugen, und eine zweizählige Schraubung um eine Axe, welche parallel zu den Prismenkanten läuft und die Mittellinie einer Prismenfläche bildet; die Schiebungscomponente dieser Schraubung ist die Länge eines Prismas.

Typus 39 (36 nach Sohncke) bildet man entweder aus Typus 26 oder aus Typus 27, als Theilsystem gebraucht, wenn acht identische Systeme irgend eines dieser Typen dadurch hergestellt werden, dass man nach einander die zur Entstehung des Typus 34 gebrauchten vierzäbligen Drebungen und die zur Erzeugung der Typen 30 und 31 angewandte zweizählige Drehung ausfuhrt. 
Typus 40 (41 nach Sohncke) entsteht entweder aus Typus 26 oder aus Typus 27 als Theilsystem, wenn acht identische Systeme des einen oder anderen dieser Typen dadurch hergestellt werden, dass man nach einander die zur Bildung des Typus 34 nöthigen vierzähligen Drehungen und die zur Erzeugung der Typen 32 und 33 erforderliche zweizählige Drehung ausführt.

Typus 41 (37 nach Sohncke) entsteht entweder aus Typus 26 oder aus Typus 27, als Theilsystem angewendet, wenn man 16 identische Systeme eines dieser Typen dadurch herstellt, dass man nach einander die vierzähligen Drehungen und die zweizählige Schraubung, welche den Typus 38 ergeben, und die zur Erzeugung der Typen 30 und 31 nöthige zweizahlige Drehung ausfürt.

Jedem der 16 So h n cke'schen Systeme der tetragonalen Gruppe entsprechend giebt es einen mindest-symmetrischen Typus homogener Structur ohne Symmetriecentren und Symmetrieebenen, der die gleichen Deckbewegungen wie das Sohncke'sche System besitzt, und in welchem daher jede Schaar gleichartiger Punkte ein solches Punktsystem bestimmt.

Von diesen 16 Typen homogener Struclur haben sechs, nämlich jene, deren Punktsysteme den Typen 26, 27, 28, 29, 34 und 38 angehören, die pyramidale Hemimorphie der Classe 27 in Sohncke's Verzeichniss der Krystallclassen ${ }^{*}$ ), und die übrigen zehn, deren Punktsysteme beziehungsweise vom Typus 30, 31, 32, 33, 35, 36, 37, 39, 40 und 41 sind, die trapezoëdrische Hemiëdrie der Glasse 22.

Es mag bemerkt werden, dass die Punktsysteme der Typen 29, 34 und 38 (29, 30 und 31 nach Sohncke), für sich betrachtet, eine höhere Symmetrie als die eben erwähnten mindest-symmetrischen homogenen Structuren besitzen, welche dieselben enthalten. Sie haben Symmetrieebenen, welche die Ebenen der Punkte schneiden und besitzen die Symmetrie der Classe 23.

\section{Die trigonale Systemgruppe.}

Die elf Sohncke'schen Systeme, welche trigonale Symmetrie haben, d. h. jene unter III A und III B seiner Uebersichtstabelle, bestehen je aus einer endlichen Anzahl mit einander identischer Systeme entweder nach dem Muster, welches Sohncke als System 15 bezeichnet oder nach dem als 16 bezeichneten, und jedes der 11 Systeme besitzt die Axen und Deckbewegungen des Systems, aus welchem es gebildel ist.

Bestimmter :

Die Typen 42 und $43=$ System 15 und 16 nach Sohncke.

Typ. 44 und 45 (System 19 und 20) entstehen aus der Ineinanderstellung zweier mit einander identischer Systeme, im ersten Fall nach dem Muster

*) Diese Zeitschr. 20, 466 . 
des Systems 15, im zweiten Fall vom System 16, wobei die Axen und Deckbewegungen der Systemcomponenten dem zusammengesetzten System eigen sind.

Typus 46 und 47 (System 23 und 24) bestehen ebenfalls bezüglich aus zwei identischen Systemen derselben Typen.

Typus 48 (System 17) besteht aus drei identischen Systemen eines der beiden Typen.

Typus 49 (System 21) bestebt aus sechs solchen identischen Systemen.

Typus 50 (System 25) ebenfalls aus sechs.

Typus 51 (System 18) ist aus neun solchen identischen Systemen zusammengesetzt.

Typ. 52 (System 22) besteht aus achtzehn solchen identischen Systemen.

Wie gesagt, besitzt in jedem Fall das zusammengesetzte System die Axen und Deckbewegungen aller identischer Theilsysteme.

Diese Sätze können fast auf dieselbe Weise wie die früheren bewiesen werden.

Um die Typen 42 und 43 ( 15 und 16 nach Sohncke) zu erhalten, theile man den Raum in gleiche, regelmässige, sechsseitige Prismen wie im Falle der hexagonalen Systemgruppe.

Die Prismenaxen können nun als dreizählige Schraubenaxen angesehen werden, deren Schiebungscomponente ein ganzes Vielfaches der Prismenlänge ist.

Man nehme nun irgendwo einen Punkt im Prismensystem an und lege durch denselben eine Ebene senkrecht zu den Prismenaxen. Mittels geeigneter Schiebungen bringe man homologe Punkte in eines von je dreien der Sechsecke, in welche diese Ebene von den Prismenkanten getheilt wird; dabei wähle man jene, welche mit dem, den ursprunglichen Punkt enthaltenden Sechseck ein symmetrisches System bilden (siehe Fig. 12). Schliesslich führe man zwei Bewegungen einer dreizähligen Schraubung um eine der Prismenaxen aus, indem man die Schiebungscomponente dieser Schraubung gleich der dreifachen Prismenlänge macht.

Dadurch werden entsprechende Punkte in eines von je neun der Prismen gebracht, welche den Raum erfullen.

Das so erhaltene Punktsystem ist ein Beispiel zu Typus 42 oder zu Typus 43 , je nachdem die angewandte Schraubung rechts oder links gewunden ist.

Die Typen 44 und 45 ( 19 und 20 nach Sohncke) entstehen beziehungsweise aus Typus 42 und 43, als Theilsystem, wenn zwei identische Systeme des betreffenden der beiden genannten Typen hergestellt werden durch eine zweizählige Drehung, deren Axe die Axe eines beliebigen Prismas schneidet und auf einer Fläche desselben senkrecht steht. Diese Drehung 
bringt die Axen der das Theilsystem entbaltenden Prismen zur Deckung, ändert aber ihre Richtung in die entgegengesetzle um.

Das durch diese Drehung erhaltene Doppelsystem der den Raum erfullenden Prismen besitzt offenbar die Axen und Deckbewegungen der Typen 42 und 43.

Die Typen 46 und 47 (23 und 24 nach Sohncke) lassen sich bezw. aus den Typen 42 und 43 herstellen, welche als Theilsystem angewendet werden, wenn zwei identische Systeme des betreffenden der beiden genannten Typen hergestellt werden mittels einer zweizäbligen Drebung, deren Axe die Axe eines beliebigen Prismas und eine Kante desselben rechtwinklig schneidet.

Diese Drehung bringt die sämmtlichen Axen der das Theilsystem entbaltenden Prismen zur Deckung, verwandelt aber ihre Richtung in die entgegengesetzte und verwechselt die verschiedenen Arten derselben.

Auch in diesem Falle besitzt das Doppelsystem der den Raum erfullenden Prismen, welches man durch diese Drehung erhält, die Axen und Deckbewegungen der Typen 42 und 43.

Typus 48 ( 17 nach Sohncke) entsteht entweder aus Typus 42 oder aus Typus 43 , als Theilsystem angewendet, wenn drei identische Systeme eines dieser Typen hergestellt werden mittels aufeinander folgender dreizähliger Drehungen um eine Axe, die mit einer Prismenaxe zusammenfällt, d. h. mit einer Axe einer der Arten dreizähliger Schraubenaxen des Theilsystems.

Typus 49 (21 nach Sohnck e) entsteht entweder aus Typus 42 oder Typus 43, als Theilsystem angewendet, wenn sechs identische Systeme des einen oder anderen der beiden Typen dadurch hergestellt werden, dass man nach einander die zur Erzeugung der Typen 44 und 4.5 angewandte zweizählige Drehung und die zur Herstellung des Typus 48 notbwendigen dreizahligen Drehungen ausfuhrt.

Typus 50 (25 nach Sohncke) entsteht entweder aus Typus 42 oder Typus 43, als Theilsystem gebraucht, wenn sechs identische Systeme eines dieser Typen dadurch hergestellt werden, dass man nach einander die zweizählige Drehung, welche zur Bildung der Typen 46 und 47 angewandt wurde, und die dreizähligen Drehungen, welche zur Erzeugung des Typus 48 erforderlich waren, ausfuhrt.

Typus 51 (18 nach Sohncke) entsteht entweder aus Typus 42 oder aus Typus 43, als Theilsystem angewandt, wenn neun identische Systeme eines dieser Typen dadurch hergestellt werden, dass man nach einander ausführt: die zur Erzeugung des Typus 48 nöthigen dreizähligen Drehungen und zwei Bewegungen einer dreizähligen Schraubung, deren Schiebungscomponente die Prismenlänge ist, um eine Axe, welche mit einer beliebigen Pris- 
menkante zusammenfällt. Es entsteht der gleiche Typus, ob nun eine Rechts- oder eine Linksschraubung angewendet wird.

In diesem Falle wird das System der Prismen nach jeder Bewegung zur Deckung gebracht und die Punkte werden in jedes dritte Prisma gelegt.

Typus 52 (22 nach Sohncke) entsteht entweder aus Typus 42 oder aus Typus 43, als Theilsystem angewandt, wenn 18 identische Systeme eines dieser Typen dadurch gebildet werden, dass man nach einander ausführt: die zweizähligen Drehungen, welche die Typen 44 und 45 erzeugen, und die dreizähligen Drebunges und dreizähligen Schraubungen, welche zur Erzeugung des Typus 51 angewendet wurden.

Jedem der elf Sohncke'schen Systeme der trigonalen Gruppe entsprechend giebt es einen mindest-symmetrischen Typus homogener Structur obne Symmetriecentren und Symmetrieebenen, welcher die gleichen Deckbewegungen wie das Sohncke'sche System besitzt und in welchem daher jede Schaar homologer Punkte ein solches Punktsystem bestimmt.

Von diesen elf Typen homogener Structur haben vier, nämlich jene, deren Punktsysteme vom Typus 42, 43, 48 und 51 sind, die hemimorphe Tetartoëdrie der Classe 20 in Sohncke's Verzeichniss der Krystallclassen $\left.{ }^{*}\right)$, und die anderen sieben, deren Punktsysteme den Typen 44, 45, $46,47,49,50$ und 52 angehören, die trapezoëdrische Tetartoëdrie der Classe 15 .

Es mag bemerkt werden, dass ein Punktsystem vom Typus 48 (17 nach Sohncke), für sich betrachtet, eine höhere Symmetrie hat, als jenes der dasselbe enthalterden, mindest-symmetrischen, homogenen Structur. Es besitat Symmetrieebenen, welche die Punklebenen schneiden, und bat die Symmetrie der Classe 16.

\section{Die rhombische Systemgruppe.}

Die neun Sohncke'schen Systeme, welche rhombische Symmetrie haben, d. s. jene unter II $B^{* *}$ ) seiner Uebersichlstabelle, bestehen je aus einer endlicben Anzahl mit einander identischer Systeme nach dem Muster eines speciellen Falles von Sohncke's System 3, und jedes der neun Systeme besitzt die Axen und Deckbewegungen der Systeme, aus welchen es besteht.

Genauer :

Typus 53 (6 nach Sohncke) entsteht aus der Ineinanderstellung zweier mit einander identischer Systeme jenes speciellen Falles von Sohncke's System 3, in welchem die Theilraumgitter rechtwinklig sind.

*) Diese Zeitschr. 20, 463.

**) Wie früher erwähnt, sind Syslem 9 und 13 nach Sobncke vom gleichen Typus. 
Typus 54 (System 14 nach Sohncke) besteht gleichfalls aus zwei solchen identischen Systemen.

T. 55 (12 nach Soh ncke) besteht ebenfalls aus zwei.

- 56 (5 n. Sohncke)

- $57(9-\quad-\quad\}$ besteht aus vier solchen identischen Systemen.

$-58(11-$

$-5917-$

$-60(10-$ f besteht aus acht solchen identischen Systemen.

- 618 besteht aus sechszehn solchen Systemen.

Wie gesagt, besitzt in jedem Falle das zusammengesetzte System die Axen und Deckbewegungen aller identischer Theilsysteme.

Diese Sätze können in fast gleicher Weise wie die früheren bewiesen werden.

Um den erwähnten speciellen Fall des Systems 3 zu erhalten, in welchem die Theilraumgitter der Punkte rechtwinklig sind, theile man den Raum in gleiche congruente Parallelepipeda, indem man drei Schaaren äquidistanter paralleler Ebenen legt, welche auf einander senkrecht stehen; die Entfernung der Ebenen jeder Schaar ist verschieden.

Man nebme nun irgendwo in dem Systeme einen Punkt an und lege durch denselben eine Ebene parallel zu den Ebenen einer der drei Schaaren. Mittelst passender Schiebungen bringe man homologe Punkte in eines von je vier der Rechtecke, in welche jene Ebene von den beiden anderen Ebenenschaaren getheilt wird; dabei wăhle man jene, welche mit dem den ursprunglichen Punkt enthaltenden Rechtecke ein symmetrisches System bilden. Schliesslich führe man eine zweizählige Schraubung um eine beliebige der Parallelepipedaxen aus, welche senkrecht auf der zuletzt gelegten Ebene stehen, indem man die Schiebungscomponente dieser Schraubung gleich der doppelten Länge eines Parallelepipeds, gemessen in der Richtung der Axe der Schraubung, macht.

Dadurch werden entsprechende Punkte in eines von je acht der den Raum erfullenden Parallelepipeda gebracht.

Das so erhaltene Punktsystem ist ein Beispiel zum verlangten speciellen Falle des Systems 3.

Typus 53 (6 nach Sohncke) entsteht aus diesem speciellen Falle des Systems 3, als Theilsystem angewendet, wenn zwei identische Theilsysteme von diesem Typus hergestellt werden durch eine zweizählige Drehung um eine Axe senkrecht zu den Axen des Theilsystems, welche so liegt, dass die Ausfuhrung der Drehung jede Art der Axen dieses Systems zur Deckung bringt; während sie die Richtung derselben umkehrt. Zu diesem Zweck muss die neue Axe mitten zwischen benachbarten Ebenen der einen der zwei Schaaren paralleler Ebenen liegen, welche parallel zu den Axen des Theilsystems sind. 
Das durch diese Drehung erhaltene Doppelsystem von Parallelepipeden, welche den haum erfullen, besitzt die Axen und Deckbewegungen des Theilsystems.

Typus 54 (14 nach Sohncke) entsteht aus demselben Theilsystem wie Typus 53, wenn man zwei identische Theilsysteme dadurch herstellt, dass man eine zweizählige Schraubung um eine zur Axe dieses Systems senkrechte Axe ausführt, welche Axe in einer Ebene der einen oder anderen der beiden zu diesen Axen parallelen Ebenenschaaren liegt. Die Schiebungscomponente der Schraubung ist die Länge eines Parallelepipeds, gemessen in der Richtung der Axe der Schraubung.

Wie im letzten Falle besitzt das durch diese Schraubung erhaltene Doppelsystem der den Raum erfullenden Parallelepipeda die Axen und Deckbewegungen des Theilsystems.

Typus 55 (12 nach Sohncke) wird ebenfalls aus demselben Theilsystem erzeugt, wenn zwei identische Theilsysteme hergestellt werden durch Anwendung einer der zweizähligen Schraubenaxen, welche zur Erzeugung des Typus 54 gebraucht wurden, als Drehungs-, statt als Schraubenaxe.

Dieselbe Bemerkung, wie die im Falle der Typen 53 und 54 gemachte, gilt auch für das erhaltene Doppelsystem der Parallelepipeda.

Typus 56 (5 nach Sohncke) entsteht aus demselben Theilsystem, wenn vier identische Theilsysteme dadurch hergestellt werden, dass man nach einander ausfuhrt: eine zweizählige Drehung, wie sie zur Erzeugung des Typus 53 angewandt wurde, und eine zweizählige Drehung um eine Axe, welche durch den Mittelpunkt eines beliebigen Parallelepipeds in der Richtung der Axen des Theilsystems gezogen ist.

Typus 57 (9 nach Sohncke) entstebt aus dem gleichen Theilsystem, wenn vier identische Theilsysteme dadurch hergestellt werden, dass man nacheinander ausfubrt: eine zweizählige Drehung, wie die zur Herstellung des Typus 53 gebrauchte, und eine zweizählige Schraubung um eine in einer Parallelepipedkante gelegene Axe, welche die Bichtung der Axen des Theilsystems hat. Die Schiebungscomponente der Schraubung ist die Länge eines Parallelepipeds. Auch eine zur Richtung der Axen des Theilsystems senkrechte Schraubung, welche diese Axen in Lagen bringt, die mitten zwischen ihren ursprunglichen Lagen sich befinden, wird den gleichen Erfolg haben.

Typus 58 (11 nach Sob ncke) entsteht aus dem nämlichen Theilsystem, wenn man vier identische Theilsysteme dadurch herstellt, dass man nacheinander ausführt : eine zweizählige Drehung, wie sie zur Erzeugung des Typus 53 nöthig war, und eine zweizäblige Drehung um eine der zur Bildung des Typus 57 gebrauchten Schraubenaxen.

Typus 59 ( 7 nach Sohnck e) entsteht aus demselben Theilsystem, wenn acht identische Theilsysteme dadurch hergestellt werden, dass man nach- 
einander ausführt : die beiden Arten zweizäbliger Drehungen, welche Typus 56 erzeuglen und eine Bewegung, welche ein Parallelepiped, das einen Punkt des erzeugenden Systems enthălt, an die. Stelle eines der Parallelepipeda bringt, welche mit demselben eine einzige Kante gemeinsam haben, z. B. eine zweizăhlige Drehung um eine seiner Kanten als Axe. Oder man kann die acht Theilsysteme erzeugen, wenn man entweder die Bewegungen, welche Typus 57 erzeugten, oder jene, welche Typus 58 ergaben, nach einander ausführt und hierauf noch eine zweizählige Drehung um eine Axe des Theilsystems bewerkstelligt.

Typus 60 ( 10 nach Soh ncke) enisteht aus dem gleichen Theilsysteme, wenn acht identische Theilsysteme dadurch bergestellt werden, dass man nach einander folgende Bewegungen ausführt: die zwei Arten zweizähliger Drehungen, welche zur Erzeugung des Typus 56 angewendet wurden, und eine solche Bewegung, welche ein Parallelepiped, das einen Punkt des Theilsystems enthält, an den Ort eines der Parallelepipeda bringt, welche mit demselben eine einzige Ecke gemein haben. Dies kann geschehen entweder dureh eine geeignete Schiebung oder durch eine zweizählige Schraubung.

Typus 61 (8 nach Sohncke) entsteht aus demselben Theilsysteme, wenn sechzehn identische Theilsysteme dadurch hergestellt werden, dass man nach einander folgende Bewegungen ausführt: die zwei Arten zweizähliger Drehungen, welche zur Bildung des Typus 56 nöthig waren, und zwei solche Bewegungen, welche ein Parallelepiped, das einen Punkt des erzeugenden Tbeilsystems entbält, an den ursprünglichen Ort zweier der Parallelepipeda bringen, welche zwei rechtwinklig zusammenstossende Kanten mit demselben gemein haben; z. B. zwei aufeinander folgende zweizählige Drehungen um irgend zwei seiner Kanten, die nicht zu einander parallel sind, als Axen.

Zu jedem der neun Sohncke'schen Systeme der rhombischen Gruppe giebt es einen entsprechend mindest-symmetrischen Typus homogener Structur ohne Symmetriecentren und Symmetrieebenen, welcher dieselben Deckbewegungen wie das Sobncke'sche Punktsystem besitzt, und in welchem daher jede Schaar homologer Punkte ein solches Punktsystem ergiebt.

Diese neun Typen homogener Structur haben die Hemiëdrie der Classe 7 in Sohncke's Verzeichniss der Krystallclassen *).

\section{Die rechtwinklig-rhomboidisch-prismatische Systemgruppe.}

Die drei So h n ck e'schen Systeme, welche durch diese Art der Symmetrie charakterisirt sind, $d$, s. jene unler II A seiner Uebersichtstabelle, bestehen

*) Diese Zeilschr. 20, 459. 
je aus einer endlichen Anzahl mit einander identischer Systeme nach dem Muster von Sobncke's System 3, und jedes der drei Systeme besitzt die Axen und Deckbewegungen der Systeme, aus welchen es besteht.

Bestimmter ausgedruickt :

Typus $62=$ Sohncke's System 3 .

Typus 63 (System 2) entsteht aus der Ineinanderstellung von zwei mit einander identischen Systemen nach dem Muster des Typus 62.

Typus 64 (System 4) besteht aus vier solchen identischen Systemen.

Um Typus 62 ( 3 nach Sohncke) zu erhalten, theile man den Raum in rbomboidische Prismen, indem man drei Schaaren paralleler, äquidistanter Ebenen legt, von denen die eine Schaar die beiden anderen rechtwink lig schneidet.

Man nehme nun irgendwo in diesem Prismensysteme einen Punkt an und lege durch denselben eine Ebene parallel zu der Schaar von Ebenen, welche auf den beiden anderen Schaaren senkrecht steht. Durch passende Schiebungen bringe man homologe Punkte in eines von je vier der Parallelogramme, in welche diese Ebene durch die beiden Ebenenschaaren, welche dieselbe rechtwinklig schneiden, getheilt wird; dabei wähle man jene, welche mit dem Parallelogramm, das den angenommenen Punkt enthält, zusammen ein symmetrisches System bilden. Schliesslich fuhre man eine zweizählige Schraubung aus um eine Axe eines der Prismen des Systems, indem man die Schiebungscomponente dieser Schraubung gleich der doppelten Länge eines Prismas macht.

Dadurch werden Punkte in eines von je acht Prismen gebracht.

Das so erbaltene Punktsystem ist ein Beispiel zu Typus 62.

Typus 63 (2 nach Sohncke) angewendet, wenn zwei identische Theilsysteme von diesem Typus mittelst einer zweizähligen Drehung, welche eine beliebige Prismenaxe zur Axe hat, hergestellt werden.

Typus 64 (4 nach Sohncke) lässt sich aus Typus 62, als Theilsystem gebraucht, erzeugen, wenn vier identische Theilsysteme von diesem Typus durch die aufeinander folgende Ausführung folgender Bewegungen hergestellt werden : die zweizählige Drehung, welche zur Erzeugung des Typus 63 erforderlich war, und eine solche Bewegung, welche ein Prisma, das einen Punkt des Theilsystems enthält, an den ursprunglichen Ort eines der Prismen bringt, welche eine Kante einer der Prismenendflächen mit ihm gemeinsam haben. Dies kann entweder durch eine geeignete Schiebung oder durch eine zweizahlige Schraubung geschehen.

Zu jedem der drei Sohncke'schen Systeme der rechtwinklig-rhomboidisch-prismatischen Gruppe giebt es einen entsprechenden mindest-symmetrischen Typus homogener Structur, ohne Symmetriecentren und Symmetrieebenen, welcher dieselben Deckbewegungen wie das Sohncke'sche Punkt- 
system besitzt, und in welchem daher jede Schaar homologer Punkte ein solches Punksystem ergieht.

Diese drei Typen homogener Structur haben die Hemimorphie der Classe $\breve{~ i n ~ S o h n c k e ' s ~ V e r z e j c h n i s s ~ d e r ~ K r y s t a l l c l a s s e n . ~}$

Es mag bemerkt werden, dass alle drei Punktsysteme, für sich allein genommen, eine höhere Symmetrie haben als die sie enthaltenden mindestsymmetrischen homogenen Structuren; sie besitzen Symmetrieebenen, welche die Punktebenen schneiden, und haben die Symmetrie der Classe 3.

\section{Die asymmetrische Systemgruppe.}

Nur ein einziges System von S o hnck e gehört hierher :

Typus $65=$ System 1 nach Sobncke.

Diesem Punktsysteme entsprechend haben wir einen mindest-symmetrischen Typus homogener Structur, ohne Symmetriecentren und Symmetrieebenen, welcher dieselben Deckschiebungen wie das Punktsystem besitzt, und in welchem daher jede Schaar homologer Punkte ein solches Punktsystem bestimmt.

Dieser Typus homogener Structur hat die Hemimorphie der Classe 2 in Sohncke's Verzeichniss der Krystallclassen.

Es mag bemerkt werden, dass das Punktsystem, für sich betrachtet, eine höhere Symmetrie hat als die mindest-symmetrischen, dasselbe enthaltenden homogenen Structuren; es besitzt Symmetriecentren und hat die Symmetrie der Classe 1 in Sohncke's Verzeichniss.

Das Obige vervollständigt den Beweis des Satzes, dass jedes der 65 Sohncke'schen Systeme aus einer endlichen Anzahl des einen oder anderen von zehn Fundamentalsystemen besteht.

Wenn die Sohncke'schen Systeme nach ihren Deckbewegungen in Glassen eingetheilt werden, bilḍen sie, wie wir gesehen, sieben Gruppen; man sieht also, dass alle möglichen homogenen Structuren in diese sieben Classen zerfallen werden, da auch sie durch diese Deckbewegungen charakterisirt sind, nämlich in :

1. Die kubische oder reguläre Gruppe.

2. Die hexagonale Gruppe.

3. Die tetragonale Gruppe.

4. Die trigonale Gruppe.

5. Die rhombische Gruppe.

6. Die rechtwinklig-rhomboidisch-prismatische Gruppe.

7. Die asymmetrische Gruppe.

Das Problem der Eintheilung einer homogenen Structur in gleiche Raumeinheiten ist offenbar ein unbestimmtes, aber die Bedingungen, welchen eine Einheit einer solchen Eintheilung genugen muss, sind augenscheinlich drei und nur drei, das heisst so lange die Structur neben ihrer 
Eintheilung nicht auch die Eigenschaft besitzt, mil ihrem eigenen Spiegelbilde*) identisch zu sein.

1. Eine Raumeinheit ist stetig.

2. Sie enthält alle Punktgattungen, d. h. jede Art eines Standpunktes, von welchem aus die Structur betrachtet werden kann.

3. Alle Punkte in ihr sind verschieden, d. h. stehen in anderer Beziehung zur ganzen Structur.

Irgend ein Theil der homogenen Struclur, welcher diesen drei Bedingungen genugt, ist eine geometrische Raumeinheit.

Wenn eine Einheit bestimmt ist, wird man die Orte der homologen Einheiten finden, indem man auf dieselbe die Deckbewegungen der Structur anwendet.

Da in jeder Drehaxe sich gleichartige Punkte vereinigen, so ist aus dem eben Gesagten klar, dass, von welcher Art auch die Eintheilung sein mag, eine Raumeinheit eine Drehaxe von jeder der in der Structur vorhandenen Arten besitzen muss und zwar in ihren Grenzflächen liegend; dass ferner kein Theil einer Drehaxe in die Raumeinheit eindringen kann, sondern längs der Grenzen derselben verlaufen muss; dass ferner z wei homologe Grenztheile, welche verschiedenen Raumeinheiten angehören, in jeder zweizähligen Axe zusammentreffen müssen, ebenso drei in jeder dreizähligen, vier in jeder vierzähligen und sechs in jeder sechszähligen Axe ${ }^{*}$ ).

Um dies zu illustriren, ist der Schnitt einer möglichen Raumeintbeilung einer homogenen Structur ohne Symmetriecentren und Symmetrieaxen beigefügt (Fig. 13), deren homologe Punkte Punktsysteme vom Typus 48 (17 nach Sohncke) bestimmen. Die Schniltebene steht beliebig senkrecht auf den dreizähligen Axen. Die Schnittpunkte der drei Arten dreizähliger Axen sind mit $A, B, C$ bezeichnet.

\section{Homogene Structuren, welche mit ihren eigenen Spiegelbildern identisch sind.}

Viele homogene Structuren besitzen eine gewisse Symmetrieeigenschaft ausser der oben definirten Eigenschaft der Homogenität. Sie sind, wenn sie als unbegrenzt gedacht werden, mit ihren eigenen Spiegelbildern identisch***).

Der Kugelhaufen, welcher bereits als Beispiel einer homogenen Struc-

*) S. S. 3. Vergl. E. von Fed orow in dieser Zeitschr. $20,62$.

**) Vergl. Krystallsysteme und Krystallstructur von H. S chönfli es 1891, S. 573.

Wenn die Raumeintbeilung an der neuen, auf S. 3 erwähnten Eigenschaft theilnimml, und die eingetheilte Structur mit ibrem eigenen Spiegelbild identisch sein soll, so wird offenbar die Raumeintheilung eine höhere Symmetrie haben. Siehe S. 59.

***) Vergl. Krystallsysteme und Krystallstructur S. 9. 
tur $\left.{ }^{*}\right)$ angeführt worden, ist ein Beispiel furr die Existenz dieser neuen Eigenschaft.

Man wird, wie gesagt, finden, dass dies die einzige Eigenschaft ist, deren Besitz den Grad der Symmetrie einer bomogenen Structur steigert; sie erhöht ihn über jenen ihrer Soh ncke'schen Punktsysteme.

Es ist klar, dass in irgend einer homogenen mit dieser Eigenschaft begabten Structur jeder Punkt in der Structur einen anderen, ihm entsprechenden Punkt hat, so dass der Anblick dér Structur als Ganzes von dem einen Punkte aus zu dem Anblicke vom anderen aus dieselbe Beziehung zeigt, wie sie zwischen der rechten und linken Hand besteht, wofern nicht thatsabchlich die Lage des Punktes eine solche ist, dass das von ihm aus erhaltene Bild der Structur mit seinem eigenen Spiegelbilde identisch ist.

Wenn so in dem erwähnten Kugelhaufen ein Punkt auf's Geradewohl angenommen wird, sei es in einer beliebigen Kugel oder in dem Raume «wischen den Kugeln, und durch denselben eine Senkrechte auf eine der Symmetrieebenen der Structur gefallt wird, so entspricht der Punkt auf dieser Senkrechten, welcher die gleiche Entfernung von der Symmetrieebene hat wie der gewählte Punkt, diesem letzteren in der beschriebenen Weise.

Oder wenn in einem Systeme, welches aus gleichen Kugeln besteht, welche mit ihren Mittelpunkten in den Punkten irgend eines Raumgitter's liegen, ein Punkt beliebig angenommen und durch denselben und einen Kugelmittelpunkt eine Gerade gezogen wird, so entspricht der Punkt dieser Geraden, welcher auf der einen Seite in der gleichen Entfernung vom Centrum liegt, wie der angenommene Punkt auf der anderen Seite, dem angenommenen Punkte in dieser Weise.

Punkte in derselben Structur, welche so mit einander verwandt sind, werden enantiomorph-ähnliche Punkte genannt werden.

Wenn eine homogene Structur mit ihrem eigenen Spiegelbilde identisch ist, und folglich, wie eben gezeigt, enantiomorph-ähnliche Punkte enthält, so ist klar, dass im Allgemeinen zu jedem regelmässigen unendlichen Punktsysteme, welches durch genau homologe Punkte in der Structur bestimmt wird ${ }^{* *}$ ), ein ihm entsprechendes anderes, mit ihm enantiomorphes System gehört, welches aus Punkten besteht, die den Punkten des ersteren Systems enantiomorph-ähnlich sind. Die einzige Ausnahme bilden die Punktsysteme, welche eine solche Symmetrie besitzen, dass sie mit ihren Spiegelbildern identisch sind ${ }^{* * *}$ ).

*) Siehe S. 2.

**) Siehe Anmerkung *) auf S. 1 .

***) Die Formen vieler Krystalle sind identisch mit ihren eigenen Spiegelbildern, und wo dies der Fall ist, werden die Krystalle, wenn sie, wie gewöhnlich angenommen, 
Wenn eine homogene Structur in Form und Zusammensetzung mit ihrem eigenen Spiegelbilde identisch ist, so ist klar, dass jede Gombination, welche aus irgend einem, durch alle genau gleichartigen Punkte der Structur bestimmten Punktsysteme einer bestimmten Art und dem ihm enantiomorphen Punktsysteme bestebt, mit dem Spiegelbilde dieser Combination identisch sein wird.

Ferner kann leicht bewiesen werden, dass die zwei enantiomorphen Systeme Deckbewegungen gemein haben werden, welche einen beliebigen Punkt eines Systems an die Stelle eines beliebigen anderen Punktes desselben Systems zu bringen vermögen.

Denn die Deckbewegungen, welche nöthig sind, um dies in jedem der zwei Systeme zu erreichen, mussen der homogenen, sie enthaltenden Structur angehören, und wenn eine dem einen Systeme wesentliche Deckbewegung nicht auch dem anderen eigen wäre, so würde die Ausführung dieser Bewegung auf Punkte stossen, welche den Punkten des letzteren Systems gleich, aber nicht darin enthalten sind. Und da die Punkte beider Systeme einander Punkt für Punkt entsprechen, so würde dies eine gleiche Erweiterung des anderen Systems in sich begreifen.

Dies widerspricht jedoch unserer Definition, dass das gegebene System aus allen genau gleichen Punkten der Structur von einer gewissen Art besteht.

Die Combination zweier enantiomorpher Sobncke'schen Systeme, welche gemeinschaftliche Deckbewegungen besitzen, ist, wie wir gesehen,

bomogene Structuren sind, jene enantiomorphen Sohncke'schen Punktsysteme enthalten.

Hieraus kann folgender interessante Schluss betreffs der Krystalle gezogen werden:

Wenn das Sohncke'sche Punktsystem, dessen Punkte Schwerpunkte einer gewissen Atom- oder Molekülart in solch' einem Krystalle bezeichnen, nicht mit seinem eigenen Spiegelbilde identisch ist, so wird ein ihm enantiomorphes Punktsystem die Orte der zu diesen Atomen oder Molekülen enantiomorphen Atome oder Moleküle markiren, und wenn Form und Eigenschaften der letzteren derart sind, dass sie mit ihren eigenen Spiegelbildern identisch sind, so werden die zwei enantiomorphen Punktsysteme beide die Lagen derselben Atom-oder Molekülart markiren.

Es ist wichtig zu bemerken, dass diese Fähigkeit der gleichen Atom- oder Molekülart, Orte zu besetzen, welche nicht genau gleichartig, sondern nur enantiomorph-ähnlich sind, mit der von Brava is und Anderen angenommenen Ansicbt übereinstimmt, dass die Stabilität der Lage der kleinsten Theile der Krystalle dem Gleicbgewichte der von diesen Elementen herrïhrenden Anziebungs- und Abstossungskräfte zuzuschreiben ist.

Denn das Spiegelbild eines beliebigen Systems von Kräften im statischen Gleichgewichte um einen Punkt liefert offenbar ein zweites System derselben Krafte um einen Punkt, welche ebenfalls im Gleichgewichte sind.

Vergleiche mit diesen Schlüssen die Vorstellungen von Schönflies bezüglich der Natur der Krystallmolekeln (s. Krystallsysteme und Krystallstructur, S. 239, 24.0 u. 616). 
eine Combination, wie sie in homogenen Structurèn vorhanden ist, die mit ihren eigenen Spiegelbildern identisch sind. Eine solehe Combination bildet ein "doppeltes System " des Herm von Fedorow, und sowohl Schönflies als Fedorow haben die verschiedenen Wege angegeben, wie doppelte Systeme aus den verschiedenen Sohncke'schen Punktsystemen aufgebaut werden können*).

Bezugglich einer erschöpfenden Behandlung dieses Problems wird der Leser auf die Werke dieser beiden Schriftsteller verwiesen; die verschiedenen doppelten Systeme werden jedoch hier aufgezählt werden, und wir werden versuchen, die Beziehungen zwischen diesen Systemen und den homogenen Structuren, in welche sie gehören, zu beleuchten. Es wird festgestellt werden, in welche der 32 Abtheilungen der Krystallformen jeder Typus eines doppelten Systems und der entsprechende Typus homogener Structur gehört.

Es ist klar, dass das System der Deckbewegungen, welche zwei in einer homogenen Structur vorhandenen enantiomorphen Punktsystemen gemein sind, mit seinem eigenen Spiegelbilde identisch sein muss, und dass also kein Sohncke'sches System, dessen System von Deckbewegungen diese Eigenschaft nicht besitzt, mit seinem Spiegelbilde zu einem doppelten Systeme combinirt werden kann, d. h. zu einer Combination zweier enantiomorpher Punktsysteme, wie sie in einer homogenen Structur vorkommen kann.

Wir werden ein doppeltes System aus irgend einem der Sohnckeschen Systeme erhalten, dessen System von Deckbewegungen die eben erwähnte Eigenschaft hat, wenn wir dieses System und das ihm enantiomorphe System in solcher Weise ineinander stellen, dass gleiche Deckbewegungen der zwei Systeme zusammenfallen.

Was die Wege anlangt, auf welchen dies geschehen kann, so sieht man leicht, dass, obgleich in allen Fällen die beiden Systeme Deckbewegungen gemeinsehaftlich haben, entsprechende Rich tungen, d. h. Richtungen, welche in den zwei so ineinander gestellten Systemen enantiomorph-gleich sind, nicht alle ubereinstimmen, so dass, wenn wir die Theile des einen Systems durch geeignete Bezeichnung unterscheiden und die entsprechenden Theile des anderen Systems in gleicher Weise bezeichnen, die Orientirung einer Schiebungsrichtung oder einer Axe im einen Systeme zuweilen die gleiche, zuweilen die entgegengesetzte Orientirung ist, wie die einer entsprechenden Linie des anderen Systems.

Es giebt drei Arten relativer Orientirung von Paaren enantiomor-

*) Vergl. "Zusammenstellung der krystallographischen Resultate des Hrn. Schönflies und der meinigen " von E. von fed or ow in St. Petersburg, diese Zeitschr. 20, besonders S. 39 und 40 . 
pher Punktsysteme, welche gemeinschaftliche Deckbewegungen besitzen, nämlich :

a) Die beiden Systeme sind in einigen Fällen in jeder Richtung entgegengesetzt orientirt, so dass jede Schiebungsrichtung oder Axe im einen Systeme die umgekehrte Orientirung hat wie jene einer beliebigen ibr entsprechenden Linie im anderen Systeme.

b) Die beiden Systeme sind in einigen Fällen entgegengesetzt orientirt in Bezug auf Ebenen von gewisser Richtung, so dass die beiden von zwei beliebigen entsprechenden Punkten auf eine gewisse Ebene (Symmetrieebene), welche diese Richtung hat, gefältten Lothe gleich sind, und diese Lothe entweder immer in derselben Geraden liegen oder eine constante Entfernung in constanter Richtung haben, so dass eine gewisse längs diẹser Ebene ausgefuhrte Schiebung der einen Schaar von Lothen, welche aus den Punkten des einen Systems gezogen sind, sie alle genau entgegengesetzt zu den entsprechenden Lothen bringt, welche von den entsprechenden Punkten des enantiomorphen Systems gefällt sind*).

c) Die beiden Systeme sind in einigen wenigen Fällen in e in er Richlung entgegengesetzt und in Richtungen, die auf dieser senkrecht stehen, rechtwinklig zu einander orientirt. Dies kann nur da vorkommen, wo das Schnittpunktnetz der Axenschaar quadratisch ist.

In einigen doppelten Systemen ist die Beziehung zwischen den sie zusammensetzenden einfacben Systemen eine solche, dass ihre relative Orientirung entweder als vom Typus a) oder vom Typus b) angesehen werden kann, d. b. sie besitzen sowohl Symmetriecentren als Symmetrieebenen. Wenn dies der Fall ist, so liegt auf der Hand, dass das gegebene System einer Deckbewegung fähig sein muss, welche, indern sie seine Orientirung in der zur ungeänderten Symmetrieebene senkrechten Richtung verlässt, die Orientirung in allen zur Symmetrieebene parallelen Richtungen umkehrt; mil anderen Worten, dasselbe muss entweder zweizählige oder vierzählige oder sechszählige Axen senkrecht zu seinen Symmetrieebenen besitzen.

Und umgekebrt: in allen doppelten Systemen, welche Axen von einer dieser drei Arlen enthalten, haben die Paare der einfachen Systeme, wenn sie eine relative Orientirung des ersten dieser zwei Typen baben, gleichzeitig die relative Orientirung des zweiten.

Wenn man die verschiedenen Wege feststellt, auf welchen enantio-

*) Der Ausdruck "Symmelrieebenen “ ist deshalb hier gebraucht, um das auszudrücken, was Schönflies als "Gleitflächen " oder "Ebenen gleitender Symmetrie " bezeichnet. Der Grund hierfür ist der Umstand, dass die Wirkung der Existenz der letzteren auf die allgemeine Symmetrie, d. h. auf die Symmetrie, welche in die oben erwăhnten 32 Classen unterschieden wird, jene der Symmetrieebenen ist, und ferner, dass das Wort "Gleitflachen a schon in einer anderen Beziehung gebraucht wird. Bezüglich einer Definition der Symmetrieebene siehe S. 50. 
morphe Sohncke'sche Punktsysteme ineinander gestellt werden können, so dass sie doppelte Systeme bilden, muss Folgendes in Bezug auf enantiomorphe Systeme im Allgemeinen bemerkt werden :

Das Spiegelbild einer Schiebung ist eine gleiche Schiebung.

Das einer Drehung ist eine gleiche Drehung.

Das einer zweizähligen Schraubung ist eine gleiche Schraubung.

Das einer vierzähligen Schraubung ist eine vierzählige Schraubung von entgegengesetzter Windung.

Das einer sechszähligen Schraubung eine Schraubung von enlgegengesetzter Windung.

\section{Doppelte Systeme, welche Symmetriecentren besitzen, nnd die Typen homogener Structuren, in welchen sie vorhanden sind.}

Wir nehmen zuerst die Art der relativen Orientirung, welche mil a) bezeichnet ist, und machen folgende allgemein gültige Anmerkungen.

Wenn alle Punkte eines beliebigen Soh ncke'schen Systems mit irgend einem Punkte im Raume verbunden werden, und jede Verbindungslinio um ihre eigene Länge über diesen Punkt hinaus verlängert wird, so bilden die so erhaltenen Punkte ein Punktsystem, welches dem gẹgebenen enantiomorph ist. Und die Orientirung des letzteren Systems ist immer dieselbe, welche Lage auch der Punkt haben mag, mit welchem die Punkte des gegebenen Systems verbunden werden, und sie ist derjenigen des ge'gebenen Systems in jeder Richtung entgegengesetzt. Auch ist die so erhaltene Combination, welche aus den beiden Sohncke'schen Punktsystemen besteht, immer identisch mit ihrem eigenen Spiegelbilde.

Damit jedoch zwei so erhaltene enantiomorphe Systeme eine solche Combination bilden können, wie sie in irgend einer bomogenen Structur vorkommen kann, müssen sie, wie wir geseben, gemeinschaftliche Deckbewegungen haben oder mit anderen Worten, sie müssen ein doppeltes System von Fedorow bilden. Und wenn sie in einer homogenen Structur vorkommen, so ist klar, da die Beziehung der zwei Systeme zur Structur enantiomorph sein muss, dass der Punkt, durch welchen die Linien gezogen sind, ein Symmetriecentrum nicht nur der zwei Systeme, sondern auch der homogenen Structur, in welcher sie zu finden sind, und ein Symmetriecentrum ihres Systems von Axen und Deckbewegungen sein wird*).

Die folgende Tabelle zeigt, welche verschiedenen Typen doppelter Systeme im Besitze von Symmetriecentren aus den Sohncke'schen Punktsystemen ableitbar sind, und giebt in jedem Falle die Lage des Symmetrie-

*) Diese Symmetriecentren entsprechen den „centres de symmetrie « von B ra va is (siehe Journal de l'Ecole Polytechnique, cahier XXXIII, p. 92, 94. Paris 1850). Vergl. Fe d o row, diese Zeitschr. 1892, 20, 28. 
centrums des doppelten Systems bezüglich der Axen oder der Raumeintheilung an, welche in dieser Abbandlung angewandt wurde, um das Sohncke'sche Punktsystem zu erhalten, von welchem es hergeleitet ist.

Um in irgend einem Falle das doppelte System zu erhalten, verbinde man alle Punkte des gegebenen Sohncke'schen Systems mit dem angegebenen Symmetriecentrum, und verlängere jede Verbindungslinie um ihre eigene Länge ưber das Centrum binaus; die dadurch erreichten Punkte bilden ein dem gegebenen Sohncke'schen Systeme enantiomorphes Punktsystem und das aus den beiden Sohncke'schen Systemen zusammengesetzte System ist das doppelte System.

Oder man kann dasselbe doppelte System folgendermassen erbalten :

Man verbinde einen beliebigen Punkt des gegebenen Systems mit dem ihm zunächst gelegenen Symmetriecentrum und verlängere die Verbindungslinie um ihre eigene Länge. Indem man nun den so gefundenen Punkt als erzeugenden Punkt gebraucht, führe man die Deckbewegungen des gegebenen Systems aus. Das so erhaltene System ist dem gegebenen enantiomorph, und beide Systeme zusammen bilden das doppelte System.

Tabelle 1 der doppelten Systeme mit Symmetriecentren.

\begin{tabular}{|c|c|c|}
\hline Nr. & $\begin{array}{l}\text { Einfaches Sohncke'sches } \\
\text { System, aus welchem das } \\
\text { doppelte System abgeleitet ist }\end{array}$ & $\begin{array}{l}\text { Lage eines Symmetriecentrams des } \\
\text { doppelten Systems }\end{array}$ \\
\hline \multicolumn{3}{|c|}{ Kubische Gruppe. } \\
\hline $1 a_{1}$ & Typus 1 (58 nach Sohncke) & $\begin{array}{l}\text { In einer der Würfelecken oder einem der Würfel- } \\
\text { mittelpunkte der Raumtheilung }{ }^{*} \text { ). }\end{array}$ \\
\hline $2 a_{1}$ & $\begin{array}{r}2(57 \mathrm{n} . \text { Sobncke) } \\
\text { 3 u. } 4(65 \text { u. } 66 \text { nach } \\
\text { Sohncke) }\end{array}$ & $\begin{array}{l}\text { Ebenso. } \\
\text { In diesem Falle ist kein doppeltes System ableitbar. }\end{array}$ \\
\hline $5 a_{1}$ & $5(62 \mathrm{n}$. S o h n cke $)$ & $\begin{array}{l}\text { In einer der Würfelecken oder einem der Würfel- } \\
\text { mittelpunkte der einen oder anderen Raum- } \\
\text { theilung }{ }^{*} \text { ). }\end{array}$ \\
\hline $6 \mathbf{a}_{\mathbf{1}}$ & $6(55 \mathrm{n}$. Sohncke) & Ebenso. \\
\hline $6 a_{2}$ & - & $\begin{array}{l}\text { Auf einer dreizăhligen Axe mitten zwischen Mittel- } \\
\text { punkt und Ecke eines Würfels der Einthei- } \\
\text { lungen. }\end{array}$ \\
\hline $7 a_{1}$ & $7(54 \mathrm{n}$. Sohncke) & Wie in Typus $5 a_{1}$ \\
\hline $7 a_{2}$ & $8\left(60 n^{-} \operatorname{soh} n c k e\right)$ & $\begin{array}{l}\text { Wie in Typus } 6 \text { a } \text {. } \\
\text { In einer Wiirfelecke der einen Aaumtheilnng**** }\end{array}$ \\
\hline $\begin{array}{l}8 a_{1} \\
8 a_{2}\end{array}$ & $\begin{array}{c}8(60 \mathrm{n} . \mathrm{Sohncke}) \\
-\end{array}$ & $\begin{array}{l}\text { In einem Würfelmittelpunkte derselben Raumthei- } \\
\text { lung. }\end{array}$ \\
\hline
\end{tabular}

*) Siebe S. 7.

**) Siehe S. 7 und 11.

***) Die Würfelecken der einen Raumtheilung sind natürlich die Würfelcentren der anderen Raumtheilung. 


\begin{tabular}{|c|c|c|}
\hline Nr. & $\begin{array}{l}\text { Einfaches Sohncke'sches } \\
\text { System, ous welcbem das } \\
\text { doppelte System abgeleitet ist }\end{array}$ & $\begin{array}{c}\text { Lage eines Symmetriecentrums des } \\
\text { doppel ten Systems }\end{array}$ \\
\hline $9 a_{1}$ & Typus 9 (69 n. Sohncke) & $\begin{array}{l}\text { Auf einer dreizłahligen Axe, wo sie von einer zwei- } \\
\text { zähligen Axe geschnitten wird. }\end{array}$ \\
\hline $9 \mathrm{a}_{2}$ & 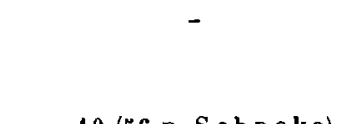 & $\begin{array}{l}\text { Auf einer dreizbihligen Axe mitten zwischen zwei } \\
\text { aufeinander folgenden Symmetriecentren des } \\
\text { Typus } 9 a_{1} \text {. }\end{array}$ \\
\hline $10 a_{1}$ & 10 (56 n. Sobncke) & $\begin{array}{l}\text { In einer Würfelecke oder einem Würfelmittelpunkte } \\
\text { oder auf einer dreizähligen Axe mitten zwischen } \\
\text { Mittelpunkt und Ecke eines beliebigen Würfels. }\end{array}$ \\
\hline $11 a_{1}$ & 11 (64 n. Sohncke) & Wie in Typus $5 a_{1}$. \\
\hline $11 a_{2}$ & - & $-6 a_{2}$. \\
\hline $12 a_{1}$ & 12 (59 n. Sobncke) & $-\quad-\quad 5 a_{1}$. \\
\hline $12 a_{2}$ & - & $-\quad-\quad 6 a_{2}$. \\
\hline $13 a_{1}$ & $13(61$ n. Sohncke) & $-10 a_{1}$ \\
\hline
\end{tabular}

\section{Hexagonale Gruppe.}

Die Typen 14, 15, 16, 17, 18, 19, 21 und $22(42,43,44,45,48,49,50$ und 51 nach $\mathrm{Sohn} \mathrm{cke)}$ liefern kein doppeltes System.

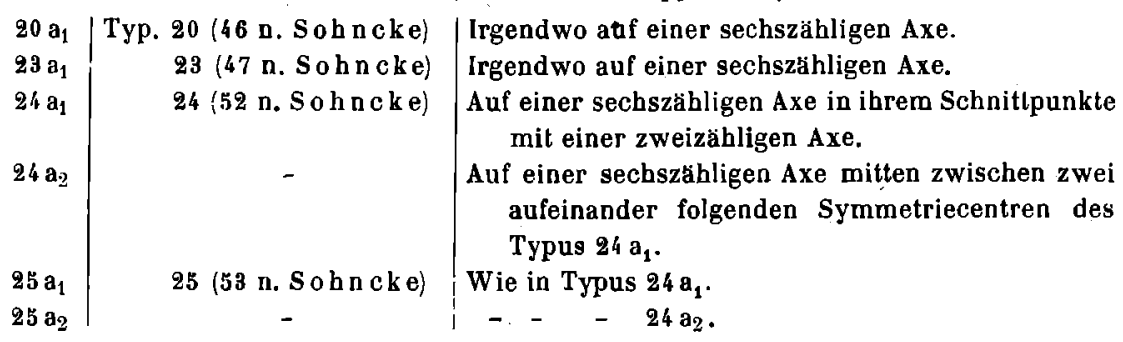

\section{Tetragonale Gruppe.}

Die Typen 26 und 27 (26 und 27 nach S o h n cke) liefern kein doppeltes System.

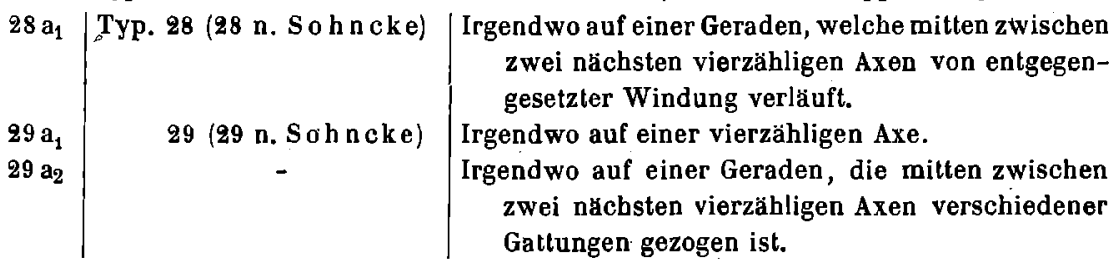

Die Typen $30,31,32$ und $33(32,33,38$ und 39 nach Sobncke) liefern kein doppeltes System.

\begin{tabular}{|c|c|c|}
\hline $\begin{array}{l}34 \mathrm{a}_{1} \\
34 \mathrm{ag}_{9}\end{array}$ & Typ. $34(30 \mathrm{n} . \mathrm{Sohncke})$ & $\begin{array}{l}\text { Irgendwo auf einer vierzähligen Axe. } \\
\text { Wie in Typus } 29 \text {. }\end{array}$ \\
\hline $35 a_{1}$ & 35. (34 n. Sohncke) & $\begin{array}{l}\text { Auf einer mitten zwischen zwei nạchsten vierzäh- } \\
\text { ligen Axen von entgegengesetzten Windungen } \\
\text { gezogenen Geraden in einem Punkte, wo sie eine } \\
\text { zweizählige Axe schneidet. }\end{array}$ \\
\hline $35 \mathrm{a}_{2}$ & - & $\begin{array}{l}\text { Auf derselben Geraden mitten zwischen zwei näch- } \\
\text { sten Symmetriecentren des Typus } 35 a_{1} \text {. }\end{array}$ \\
\hline
\end{tabular}




\begin{tabular}{|c|c|c|}
\hline $\mathrm{Nr}$. & $\begin{array}{l}\text { Einfaches Sohncke'sches } \\
\text { Sygtem, aus welchem das } \\
\text { doppelte System abgeleitet ist }\end{array}$ & $\begin{array}{c}\text { Lage eines Symmetriecentrums des } \\
\text { doppelten Systems }\end{array}$ \\
\hline $36 a_{1}$ & Typus $36(35 \mathrm{n}$. Sohncke) & $\begin{array}{l}\text { Auf einer vierzähligen Axe in ihrem Schnittpunkte } \\
\text { mit einer der zweizäbligen Axen, welche vier- } \\
\text { zählige Axen verschiedener Arten schneidet. }\end{array}$ \\
\hline $36 a_{2}$ & - & $\begin{array}{l}\text { Auf einer vierzähligen Axe mitten zwischen zwei } \\
\text { nächsten Symmetriecentren des Typus } 36 a_{1} \text {. }\end{array}$ \\
\hline $36 a_{3}$ & - & $\begin{array}{l}\text { Auf einer Geraden, welche mitten zwischen zwei } \\
\text { nächsten vierzłhligen Axen verschiedener Arten } \\
\text { verläuft, in einem Punkte, wo sie eine zweizäh- } \\
\text { lige Axe schneidet. }\end{array}$ \\
\hline $36 a_{4}$ & 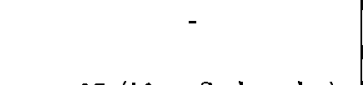 & $\begin{array}{l}\text { Auf derselben Geraden mitten zwischen zwei näch- } \\
\text { sten Symmetriecentren des Typus } \mathbf{9 6} \mathbf{a}_{3} \text {. }\end{array}$ \\
\hline $37 a_{1}$ & $37(40$ n. Sohncke) & $\begin{array}{l}\text { Auf einer vierzähIigen Axe, wo sie eine Querebene } \\
\text { trifft, die zweizählige Axen enthält. }\end{array}$ \\
\hline $37 \mathrm{a}_{2}$ & - & $\begin{array}{l}\text { Auf einer vierzábligen Axe mitten zwischen zwei } \\
\text { nächsten Symmetriecentren des Typus } 37 \mathrm{a}_{1} \text {. }\end{array}$ \\
\hline 37 a & - & $\begin{array}{l}\text { Auf einer Geraden, welche mitten zwischen zwei } \\
\text { nächsten vierzähligen Axen von entgegengesetz- } \\
\text { - ter Orientirung verläuft, in einem Punkte, wo } \\
\text { sie eine zweizählige Axe schneidet. }\end{array}$ \\
\hline $37 a_{4}$ & - & $\begin{array}{l}\text { Auf derselben Geraden mitten zwischen zwei näch- } \\
\text { sten Symmetriecentren des Typus } 37 a_{3} \text {. }\end{array}$ \\
\hline $38 a_{1}$ & $38(31$ n. Sohncke) & Irgendwo auf einer vierzähligen Drehaxe. \\
\hline $39 a_{1}$ & $39(36$ n. Sohncke) & Wie in Typus $36 a_{1}$. \\
\hline $39 a_{2}$ & - & $-\quad-\quad-\quad 36 \mathrm{a}_{2}$ \\
\hline $39 a_{3}$ & - & $-\quad-\quad 36 a_{3}$. \\
\hline $39 \mathbf{a}_{4}$ & - & $-\quad 36 \mathrm{a}_{4}$. \\
\hline $40 a_{1}$ & $40(41$ n. Sohncke) & $-\quad 37 a_{1}$. \\
\hline $40 a_{2}$ & - & $-\quad 37 a_{2}$. \\
\hline $40 a_{3}$ & - & $-\quad-\quad 37 \mathbf{a}_{3}$ \\
\hline $40 a_{4}$ & - & $-\quad 37 a_{4}$ \\
\hline $41 a_{1}$ & $41(37$ n. Sohncke) & $\begin{array}{l}\text { Auf einer vierzähligen Axe in ihrern Schnittpunkte } \\
\text { mit einer zweizähligen Axe. }\end{array}$ \\
\hline $41 \mathrm{a}_{2}$ & - & $\begin{array}{l}\text { Auf eirrer vierzähligen Axe mitten zwischen zwei } \\
\text { nächsten Symmetriecentren des Typus }{ }^{4} \mathrm{a}_{1} \text {. }\end{array}$ \\
\hline
\end{tabular}

\section{Trigonale Gruppe.}

Die Typen 42, 43, 44, 45, 46 und $47(15,16,19,20,23$ und 24 nach Sohncke) liefern kein doppeltes System.

\begin{tabular}{|c|c|c|}
\hline $48 a_{1}$ & Typ. 48 (17 n. Sobncke) & Irgendwo auf einer dreizähligen Axe irgend einer \\
\hline $49 a_{1}$ & $49(21$ n. Sohncke) & $\begin{array}{l}\text { der drei Arten. } \\
\text { Auf einer dreizäbligen Axe in ibrem Schniltpunkte } \\
\text { mit einer zweizähligen Axe. }\end{array}$ \\
\hline 9 & - & $\begin{array}{l}\text { Auf einer dreizähligen Axe mitten zwischen zwe } \\
\text { ntichsten Symmetriecentren des Typus } 49 a_{1} \text {. }\end{array}$ \\
\hline & $50(25$ n. Sohncke) & Wie in Typus $49 a_{1}$. \\
\hline & - & $-\quad-49 \mathrm{a}_{2}$. \\
\hline
\end{tabular}




\begin{tabular}{|c|c|c|}
\hline Nr. & $\begin{array}{l}\text { Einfaches So Lncke'sches } \\
\text { 8ystem, sus welchem das } \\
\text { doppelte System abgeleitet ist }\end{array}$ & $\begin{array}{c}\text { Lage eines Symmetriecentrums des } \\
\text { doppelten Systems }\end{array}$ \\
\hline $51 a_{1}$ & Typus 51 (18 n. Sohncke) & Irgendwo auf einer dreizähligen Drehaxe. \\
\hline $52 a_{1}$ & $52(22$ n. Solı ncke) & $\begin{array}{l}\text { Auf einer dreizłhligen Drehaxe in ihrem Schnitt- } \\
\text { punkte mit einer zweizähligen Axe. }\end{array}$ \\
\hline $52 a_{2}$ & - & $\begin{array}{l}\text { Auf einer dreizähligen Drehaxe mitten zwischen } \\
\text { zwei nächsten Symmetriecentren des Typ. } 52 a_{1} \text {. }\end{array}$ \\
\hline
\end{tabular}

\section{Rhombirche Gruppe.}

$53 a_{1}$ - Typ. 53 (6 nach Sohncke) Auf einer zweizăhligen Schraubenaxe irgend einer Art in ihrem Schnittpunkle mit einer auf ihr senkrechten zweizähligen Drehaxe.

Auf einer Linie, welcbe mitten zwischen zwei nächsten zweizähligen Schraubenaxen verschiedener Arten gezogen ist, im Schniltpunkte mit einer auf ibr senkrechten Axe.

Auf derselben Linie mitten zwischen zwei nächsten Symmetriecentren des Typus $53 \mathrm{a}_{2}$.

Auf einer Geraden, welche mitten zwischen zwei Scbraubenaxen von verschiedenen Arten verlauft, welche einander diagonal nächsibenachbart sind, im Schnittpunkte dieser Geraden mit einer auf ihr senkrechten Ebene, welche zweizählige Axen entbält.

$54 a_{1} \quad 54(14$ n. Sobncke)

Ein Punkt mitten zwischen zwei nächstbenachbarten Axen in allen drei zu einander senkrechten Richlungen.

Auf einer Axe in ihrem Schniltpunkte mit einer auf ihr senkrechten Ebene, welche andere Axen enthält.

Der Schnittpunkt zweier Schraubenaxen.

Auf einer Schraubenaxe mitten zwischen zwei aufeinander folgenden Symmetriecentren von $55 \mathbf{a}_{1}$.

Auf einer Drehaxe in einer zu ihr 'senkrechten Ebene, welche Schraubenaxen enthált.

Auf einer Drehaxe mitten zwischen Symmelriecentren des Typus $55 a_{3}$.

So gelegen, dass es gleichzeitig mitten zwischen Symmetriecentren des Typus $55 a_{2}$ und auch zwischen jenen von $55 \mathrm{a}_{4}$ sich befindet.

So gelegen, dass es gleichzeitig mitten zwischen Symmetriecentren des Typus $55 a_{1}$ und auch zwischen jenen von 55 a sich befindet.

Der Schniltpunkt dreier Drehaxen.

Auf einer Drehaxe mitten zwischen zwei aufeinander folgenden Symmetriecentren von $56 \mathrm{a}_{1}$. von den Drehaxen umsäumt werden. 


\begin{tabular}{|c|c|c|}
\hline Nr. & $\begin{array}{l}\text { Einfaches Soh ncke'sehes } \\
\text { System, aus welchem das } \\
\text { doppelte System abgeleitet ist }\end{array}$ & $\begin{array}{l}\text { Lage eines Symmetriecentrums des } \\
\text { doppelten Systems }\end{array}$ \\
\hline $56 a_{4}$ & Typus 56 (5 nach Sohncke) & $\begin{array}{l}\text { So gelegen, dass es gleichzeitig mitten zwischen } \\
\text { Symmelriecentren von } 56 \mathrm{a}_{2} \text { und zwischen jenen } \\
\text { von } 56 \mathrm{a}_{3} \text { sich befindet. }\end{array}$ \\
\hline $57 a_{1}$ & $57(9$ n. Sohncke) & $\begin{array}{l}\text { Der Schnittpunkt einer Schrauben- und : einer } \\
\text { Drehaxe. }\end{array}$ \\
\hline $57 \mathrm{a}_{2}$ & - & $\begin{array}{l}\text { Auf einer Linie mitten zwischen zwei nächsten } \\
\text { Schraubenaxen von verschiedenen Arten, in } \\
\text { ihrem Schnittpunkte mit einer Drehaxe. }\end{array}$ \\
\hline $58 a_{1}$ & 58 (11 n. Sohncke) & $\begin{array}{l}\text { Der Schnittpunkt einer Schrauben- und einer } \\
\text { Drehaxe. }\end{array}$ \\
\hline $\mathbf{5 8} \mathrm{a}_{2}$ & - & Wie in Typus $57 \mathbf{a}_{2}$. \\
\hline $59 a_{1}$ & 59 (7 nach Sohncke) & Der Schnittpunkt dreier Drehaxen. \\
\hline $59 \mathrm{a}_{2}$. & - & $\begin{array}{l}\text { Auf einer zweizähligen Axe senkrecht zur Ebene } \\
\text { von } S \text { ohn cke's Fig. } 7 \text {, Taf. } 1 \text { milten zwischen } \\
\text { zwei aufeinander folgenden Symmetriecentren } \\
\text { des Typus } 59 \mathrm{a}_{1} \text {. }\end{array}$ \\
\hline $59 a_{3}$ & - & $\begin{array}{l}\text { Auf einer Geraden mitten zwischen zwei der letzt- } \\
\text { genannten Axen, im Schnittpunkte derselben mit } \\
\text { einer auf ihnen senkrechten zweizähligen Axe. }\end{array}$ \\
\hline $59 \mathrm{a}_{4}$ & - & $\begin{array}{l}\text { Auf der gleichen Geraden mitten zwischen zwei } \\
\text { aufeinander folgenden Symmetriecentren des } \\
\text { Typus } 59 \mathrm{a}_{3} \text {. }\end{array}$ \\
\hline $60 a_{1}$ & $60(10$ n. Sohncke) & Der Schnittpunkt dreier Drehaxen. \\
\hline $60 \mathrm{a}_{2}$ & - & $\begin{array}{l}\text { Auf einer zweizähligen Drehaxe mitten zwischen } \\
\text { zwei benachbarten Schnittpunkten von zweizäh- } \\
\text { ligen Axen verschiedener Art mit derselben. }\end{array}$ \\
\hline $61 a_{1}$ & $61(8$ n. Sobncke) & Der Schnittpunkt dreier Drehaxen. \\
\hline $61 \mathrm{a}_{2}$ & - & $\begin{array}{l}\text { Im Halbirungspunkte einer Geraden, welche diago- } \\
\text { nal zwei nächste Symmetriecentren vom Typus } \\
61 \mathrm{a}_{1} \text { von verschiedener Art verbindet. }\end{array}$ \\
\hline
\end{tabular}

\section{- Rechtwinklig-rhomboidisch-prismatische Gruppe.}

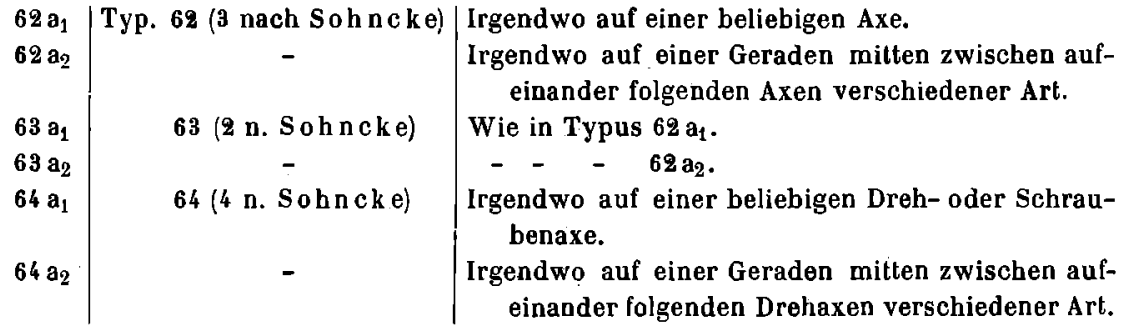

\section{Asymmetrische Gruppe.}

$65 a_{1} \mid .65$ ( 1 n. Sohncke) | Ein beliebiger Punkt im Raume. 
Jedem solchen Typus eines doppelten Systems entsprechend giebt es einen Typus homogener Structur, welcher mit seinem eigenen Spiegelbilde identisch ist, dessen enantiomorphe Punktsysteme unendlich viele doppelte Systeme von diesem Typus bilden und welcher sowohl Symmetriecentren als Deckbewegungen mit diesen doppelten Systemen gemein hat.

Von den 17 so erhaltenen Typen homogener Structur der kubischen Gruppe mil Symmetriecentren zeigen sieben, nämlich jene, deren Punktsysteme von den Typen 1, 2, 6, 7 und 10 sind, die dodekaëdrische. Hemiëdrie der Classe 31 in Sohncke's Verzeichniss der Krystallclassen, und die abrigen zehn die Holoëdrie der Classe $28 *$ ).

Von den sechs Typen homogener Structur der hexagonalen Gruppe mit Symmetriecentren stellen jene zwei, deren Punktsysteme den Typen 20 und 23 angehören, die bipyramidale Hemiëdrie der Classe 11 in Sohncke's Verzeichniss dar und die abrigen vier die Holoëdrie der Glasse 9.

Von den 26 Typen der tetragonalen Gruppe zeigen jene sechs, deren Punktsysteme den Typen 28, 29, 34 und 38 angebören, die bipyramidale Hemiëdrie der Classe 23, die übrigen 20 die Holoëdrie der Classe 21 in Sohncke's Verzeichniss.

Von den acht Typen der trigonalen Gruppe zeigen zwei, nämlich jene, deren Punktsysteme den Typen 48 und 51 angehören, die rhomboëdrische Tetartoëdrie der Classe 14, die ubrigen sechs die skalenoëdrische Hemiëdrie der Classe 12.

Alle 28 Typen der rhombischen Gruppe zeigen die Holoëdrie der Classe 6.

Alle sechs Typen der rechtwinklig-rhomboidisch-prismatischen Gruppe zeigen die Holoëdrie der Classe 3.

Der einzige asymmetrische Typus mil Symmetriecentren hat die Holoedrie der Classe 1.

Diese sämmtlichen 92 Typen homogener Structur, welche Symmetriecentren enthalten, zeigen holomorphe Symmetrie, alle anderen Typen homogener Structur sind hemimorph**).

Hinsichtlich aller Gruppen wird, wie oben festgestellt wurde ***), eine homogene Structur oder ein doppeltes System, welche sowohl Symmetriecentren als auch zweizählige, vierzählige oder sechszählige Axen besitzt, Symmetrieebenen $\dagger$ ) haben rechtwinklig zu diesen Axen.

*) Siehe diese Zeitscbr. 20,59 u. 60 und 20,467 u. 466 .

**) Bezüglich einer Definition der Hemimorphie siehe Grolh's Pliysikalische Krystallographie, S. 228.

***) Siehe S. 42.

t) Dieser Ausdruck ist hier im erweiterten Sinne gebraucht; s. Anmork. *) S. 42. Groth, Zeitsehrift f. Krystallogr. XXIII. 
2. Doppelte Systeme, welche Symmetrieebenen, aber kine Symmetriecentren besitzen, und die Typen homogener Structaren, in welchen sie vorkommen.

Bezúglich der doppelten Systeme und homogenen Structuren, deren entsprechende einfache Systeme die als b) bezeichnete relative Orientirung, nicht aber die als a)*) bezeichnete haben, ist Folgendes allgemein gultig:

Die Symmetrieebenen, welche die so charakterisirten Systeme und Structuren besitzen, können folgendermassen definirt werden :

Eine Symmetrieebene ist eine Ebene, welche eine homogene Structur so theilt, dass der Theil der Structur, welcher auf der einen Seite der Ebene liegt, dem auf der anderen Seite enantiomorph ist, während gleichzeitig der Winkel, welchen irgend eine lineare oder ebene Richtung **) der Structur mit irgend einer ihr enantiomorph-ähnlichen Richtung einschliesst, in allen Fälen von der Richtung der Symmetrieebene $\left.{ }^{* * *}\right)$ halbirt wird.

Denn nach dieser Definition können enantiomorph-ähnliche Punkte auf entgegengesetzten Seiten der Symmetriecentren einander entweder direct entgegengesetzt sein oder es auch nicht sein. Und wenn sie es nicht sind, und wenn von einem beliebigen Punkte in der Structur und ebenso von dem ihm entsprechenden enantiomorph-äbnlichen Punkte auf der entgegengesetzten Seite der Symmetrieebene Senkrechte auf die letztere gefällt und ibre Fusspunkte vereinigt werden, so sind die beiden Lothe einander gleich und die Verbindungslinie hat dieselbe Länge und Richtung, wo auch immer der gewählte Punkt in der Structur liegen mag. Und daher haben die enantiomorphen Systeme die mit b) bezeichnete relative Orientirung.

Was ferner die Art der Schiebung der auf der einen Seite der Symmetrieebene liegenden balben Structur betrifft, welche enantiomorph-ähnliche Punkte einander gegentaberstellen soll, wenn sie sich nicht schon gegenuberstehen, so bemerken wir Folgendes:

Das Spiegelbild einer Schiebung ist eine gleiche Schiebung. Wenn also eine gewisse Schiebung einen Punkt auf der einen Seite der Ebene an einen Ort bringt, so dass er dem ibm enantiomorph-ähnlichen Punkte auf del anderen Seite gegenuber liegt, so wird eine gleiche Schiebung der letzteren in der gleichen Richtung ihn einem entsprechenden Punkte gegenüber bringen. Beide Schiebungen zusammen müssen daher eine Schiebung

*) Siehe S. 42.

**) Z. B. eine Punktebene irgend eines Punktsyslems der Structur.

***) Siche Anmerk. *) S. 42. Vergl. Physikalische Kryslallographie von P. Groth 1885, S. 214 und Naumann-Zirkel, Elemente der Mineralogie 1885, S. 11.

Dieselbe Definition gilt für Symmetrieebenen von Structuren, welche auch Symmetrieoentren besitzen. 
der homogenen Structur ausmachen. Mit anderen Worten: Die Schiebung, welche nöthig ist, oin einfaches System demanderen, a uf der anderen Seite der Symmetrieebene gelegenen, gegenuberzu stellen, istimmerdie Hälfte einer Schiebung derhomogenen Structur.

Die folgende Tabelle giebt an, welche verschiedenen Typen doppelter Systeme, die Symmetrieebenen, aber nicht Symmetriecentren besitzen, von den Sohncke'schen Punktsystemen ableitbar sind, und sie giebt in jedem Falle die Lage einer Symmetrieebene des doppelten Systems in Bezug auf die Axen an, und in Fällen, wo enantiomorph-ähnliche Punkte nicht entgegengeselzt sind, zeigt sie die Schiebung, welche e in einfaches System erfahren musste, um entsprechende Punkte der beiden einfachen Systeme auf beiden Seiten der Symmetrieebene einander gegenuber zu stellen.

Um in irgend einem Falle das doppelte System zu erbalten, fälle mun von jedem Punkte des gegebenen So hncke'schen Syslems eine Senkrechte auf die Symmetrieebene, und verlängere sie, bis die Länge derselben nach der anderen Seite der Symmetrieebene gleich der Länge auf der ersten Seite ist.

Wenn die enantiomorph-ähnlichen Punkte einander gegenüberliegen auf beiden Seiten der Symmetrieebene, so bilden die dadurch erlangten Punkte ein dem gegebenen Systeme enantiomorphes System mit den gleichen Deckbewegungen, und beide Systeme zusammen werden das doppelte Syslem bilden.

Wenn jedoch eine Schiebung des einen einfachen Systems nothwendig ist, um die enantiomorph-ähnlichen Punkte einander gegenuber zu stellen, dann müssen die Theile der Senkrechten, welche uber die Symmetrieebene binaus verlängert sind, dieser Schiebung unterworfen werden.

Wenn dies geschehen, werden die Endpunkte der verschobenen Senkrechten die Lagen der Punkte des dem gegebenen Systeme enantiomorphen Systems bezeichnen, und beide Systeme zusammen werden das doppelte System bilden.

Oder es kann, wie fruher, das doppelte System erhalten werden, indem man zuerst einen einzigen Punkt des enantiomorphen Systems bestimmt und dann die Lagen der anderen Punkte dadurch ormittelt, dass man die Deckbewegungen des gegebenen Sohncke'schen Systems dem einzigen zuerst erhaltenen Punkte ortheilt, den man als erzeugenden Punkt gebraucht. 
Tabelle 2 der doppelten Systeme mit Symmetrie日benen, aber ohne Symmetriecentren.

\begin{tabular}{c|c|c|c|}
\hline Nr. & $\begin{array}{c}\text { Einfaches Boh n c ke'sches } \\
\text { System, von welchem das } \\
\text { doppelte System abgeleitet ist }\end{array}$ & $\begin{array}{c}\text { Lage einer Symmetrieebene des } \\
\text { doppelten Systems }\end{array}$ & $\begin{array}{c}\text { Schiebung, wenn eine } \\
\text { erforderlich ist, die enan- } \\
\text { tiomorphen \$ysteme auf } \\
\text { beiden Seiten der 8ym- } \\
\text { metrieebene einander } \\
\text { gegenüberzustellen *) }\end{array}$ \\
\hline \hline
\end{tabular}

\section{Kubische Gruppe.}

Typus 1 (58 nach Soh n cke) liefert kein doppeltes System ausser jenem in Tabelle 1. \begin{tabular}{l|l|l}
$\mathbf{2 b}_{1}$ & Typus $2(57 \mathrm{n}$. Sohncke) & Senkrecht auf einer Würfel-|EinehalbeSchiebung
\end{tabular} fläche und eine dreizählige lăngs der dreizäbAxe entbaltend. $\quad$ ligen Axe.

Die Typen 3 und 4 (65 und 66 nach $S$ ohn cke) liefern kein doppeltes System.

Typus 5 (62 nach So hncke) liefert kein doppeltes System ausser jenem in Tab. 1.

\begin{tabular}{|c|c|c|c|}
\hline $6 b_{1}$ & Typus 6 ( $55 \mathrm{n}$. Soh n cke) & $\begin{array}{l}\text { Senkrecht auf einer Würfel- } \\
\text { fläche und eine dreizählige } \\
\text { Axe enthaltend. }\end{array}$ & Keine. \\
\hline $6 b_{2}$ & - & - & $\begin{array}{c}\text { EinehalbeSchiebung } \\
\text { längs dieser Axe. }\end{array}$ \\
\hline $\begin{array}{l}7 b_{1} \\
7 b_{2}\end{array}$ & $\begin{array}{c}-7(54 \text { n. Sobncke }) \\
-\end{array}$ & - & $\begin{array}{l}\text { Keine. } \\
\text { EinehalbeSchiebung } \\
\text { längs dieser Axe. }\end{array}$ \\
\hline
\end{tabular}

Die Typen 8, 9, 11, 12 und $13(60,63,64,59$ und 61 nach Sohncke) liefern kein doppeltes System ausser jenen in Tab. 1.

$10 \mathrm{~b}_{1} \mid$ Typ. 10 (56 n, Sohncke) Senkrecht auf einer Würfel-| Keine. fläche und eine dreizählige Axe enthaltend.

\section{Hexagonale Gruppe.}

Die Typen 14, 15, 16, 17, 18 und $19(42,43,44,45,48$ und 49 nach Sob n cke) liefern kein doppeltes System.

\begin{tabular}{|c|c|c|c|}
\hline $20 b_{1}$ & Typ. 20 (46 n. Sohncke) & $\begin{array}{l}\text { So gelegt, dass sie nächste sechs- } \\
\text { zählige Axen }\end{array}$ & Keine. \\
\hline & & $\begin{array}{l}\text { oder übornächste Axen ent- } \\
\text { bält. }\end{array}$ & $\begin{array}{l}\text { Eine halbeSchiebung } \\
\text { längs der sechs- } \\
\text { zăhligen Axen. }\end{array}$ \\
\hline $20 b_{2}$ & - & $\begin{array}{l}\text { Sogelegt, dass sie nächste sechs- } \\
\text { zăhlige Axen enthält } \\
\text { o der übernächste Axen. }\end{array}$ & $\begin{array}{l}\text { EinehalbeScbiebung } \\
\text { längs dieser Axen. } \\
\text { Keine. }\end{array}$ \\
\hline
\end{tabular}

Die Typen 21 und 22 (50 und 51 nach $S$ oh ncke) liefern kein doppeltes System. \begin{tabular}{l|c|c|c}
$23 b_{1}$ & Typ. $23(47 \mathrm{n}$. Sohnck e) & $\begin{array}{c}\text { Durch nächste sechszählige } \\
\text { Axen gelegt. }\end{array}$ & $\begin{array}{l}\text { Keine: } \\
23 b_{2}\end{array}$ \\
- & - & $\begin{array}{c}\text { Eine halbeSchiebung } \\
\text { längs dieser Axen. }\end{array}$
\end{tabular}

Die Typen 24 und 25 (52 und 53 nach $S$ ohncke) liefern kein doppeltes System ausser jenen in Tabelle 1.

*) Diese Schiebungen sind in allen Fällen in Termen der Schiebungen des gegebenen Sohncke'schen Systems gegeben (siehe S. 50). 


\begin{tabular}{c|c|c|c|c|}
\hline NF. & $\begin{array}{c}\text { Einfaches Sohncke'sches } \\
\text { System, von welchem das } \\
\text { doppelte System abgeleitet ist }\end{array}$ & $\begin{array}{c}\text { Lage einer Symmetrieebene des } \\
\text { doppelten Syotems }\end{array}$ & $\begin{array}{c}\text { Schiebung, wenn eine } \\
\text { erforderlichigt, die enan- } \\
\text { tiomorphen Systeme auf } \\
\text { beiden Seiten der Sym- } \\
\text { metrieebene einander } \\
\text { gegenüberzustellen }\end{array}$ \\
\hline
\end{tabular}

\section{Tetragonale Gruppe.}

Die Typen 26 und 27 (26 und 27 nach So hnck e) liefern kein doppeltes System.

\begin{tabular}{|c|c|c|c|}
\hline $28 b_{1}$ & Typ. 28 (28 n. Sohncke) & $\begin{array}{l}\text { Mitten zwischen zwei nächsten } \\
\text { vierzähligen Axen von ent- } \\
\text { gegengesetzter Windung und } \\
\text { senkrecht auf der Ebene der- } \\
\text { selben. }\end{array}$ & Keine. \\
\hline $28 b_{2}$ & - & - & $\begin{array}{l}\text { EinehalbeSchiebung } \\
\text { längs einer vier- } \\
\text { zähligen Axe. }\end{array}$ \\
\hline $29 b_{1}$ & $-\quad 29(29$ n. Sohncke) & $\begin{array}{l}\text { Durch nächste vierzählige Axen } \\
\text { der zwei Arten gelegt. }\end{array}$ & Keine. \\
\hline $29 b_{2}$ & - & - & $\begin{array}{l}\text { Eine halbeSchiebung } \\
\text { längs einer vier- } \\
\text { zähligen Axe. }\end{array}$ \\
\hline $29 b_{3}$ & - & $\begin{array}{l}\text { Mitten zwischen nächsteñ Sym- } \\
\text { metrieebenen von } 29 \mathrm{~b}_{1} \text { hin- } \\
\text { durchgehend. }\end{array}$ & Keine. \\
\hline $29 b_{4}$ & - & - & $\begin{array}{l}\text { Eine halbeSchiebung } \\
\text { längs einer vier- } \\
\text { zähligen Axe. }\end{array}$ \\
\hline
\end{tabular}

Die Typen 30, 31, 32 und 33 (32, 33, 38 und 39 nach Sohncke) liefern kein doppeltes System.

\begin{tabular}{c|c|cc|}
$34 b_{1}$ & Typ. 34 (30 n. Sohncke) & Wie im Falle dès Typus $29 b_{1}$. \\
$34 b_{2}$ & - & - & $29 b_{2}$. \\
$34 b_{3}$ & - & - & $29 b_{3}$. \\
$34 b_{4}$ & - & - & $29 b_{4}$.
\end{tabular}

Die Typen 35, 36, 37, 39, 40 und 41 (34, 35, 40, 36, 41 und 37 nach $S$ oh $n$ cke) liefern keine doppelten Systeme ausser jenen in Tabelle 1.

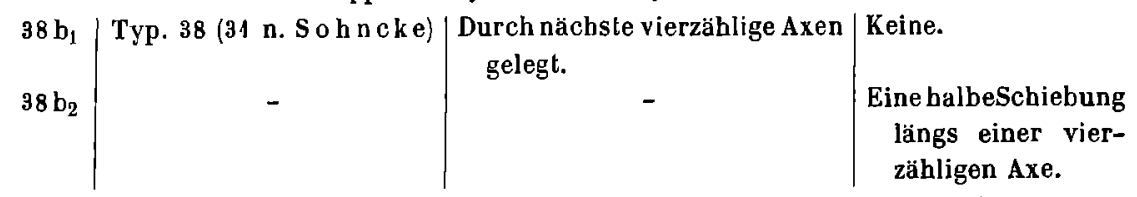

Die Typen 53, 54 und 55 (6,14 und 12 nach Sohncke), welche so specialisirt sind, dass die Axen in einer Richtung eine tetragonale Anordnung habe $\mathrm{n}$, liefern keine doppelten Systeme ausser jenen in Tabelle 1.

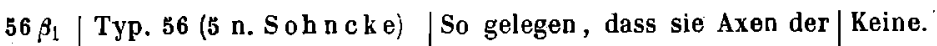
so specialisirt tetragonal angegeordneten Schaar enthält, und die übrigen zwei Scbaaren auf einander senkrechter Axen unter Winkeln von $45^{0}$ schneidet. 


\begin{tabular}{|c|c|c|c|}
\hline Nr. & $\begin{array}{l}\text { Einfaches Sohncke'sches } \\
\text { System, von welchem des } \\
\text { doppelte System abgeleitet ist }\end{array}$ & $\begin{array}{l}\text { Lage einer Symmetrieebene des } \\
\text { doppelten Systems }\end{array}$ & $\begin{array}{l}\text { Schiebung, wenn eine } \\
\text { erforderlich ist, die enan- } \\
\text { tiomorphen Systeme auf } \\
\text { beiden Selten der Sym- } \\
\text { metrieebene einander } \\
\text { gegenüberzustellen }\end{array}$ \\
\hline $56 \beta_{2}$ & $\begin{array}{l}\text { Typus } 56 \text { (5n. Sohncke) } \\
\text { so specialisirt }\end{array}$ & $\begin{array}{l}\text { So gelegen, dass sie Axen der } \\
\text { tetragonal etc. wie vorher. }\end{array}$ & $\begin{array}{l}\text { EinehalbeSchiebung } \\
\text { längs der tetrago- } \\
\text { nal angeordneten } \\
\text { Axen. }\end{array}$ \\
\hline $56 \beta_{3}$ & - & - & $\begin{array}{l}\text { Eine halbe trans- } \\
\text { verse Schiebung } \\
\text { längs der Symme- } \\
\text { trieebene. }\end{array}$ \\
\hline $56 \beta_{4}$ & - & - & $\begin{array}{l}\text { Die Resultirende der } \\
\text { letzten zwei Schie- } \\
\text { bungen. }\end{array}$ \\
\hline
\end{tabular}

Die Typen 57 und 58 (9 und 11 nach Soh n cke) liefern, so specialisirt, kein doppeltes System ausser jenen in Tabelle 1 .
$59 \beta_{1}$ Typ. 59 (7 n. Sohncke) so specialisirt; die tetra- gonal angeord neten Axen sind die horizontal. Axen in Sohncke's Figur.

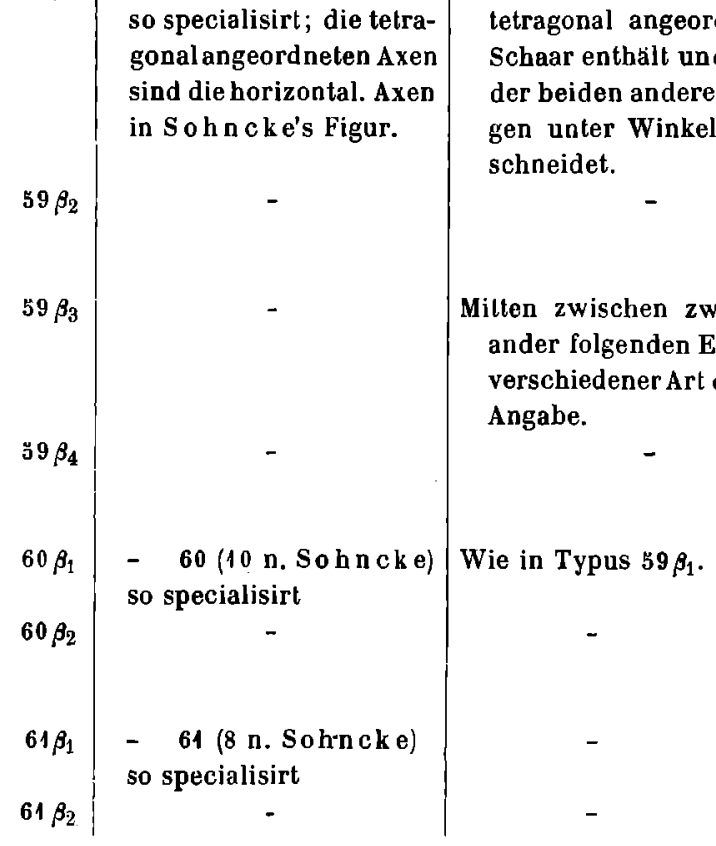 tetragonal angeordneten der beiden anderen Richlun- schneidet. So gelegen, dass sie Axen der Schaar enthält und die Axen gen unter Winkeln von $45^{\circ}$
Koine.
$\frac{1}{2}$ Schiebung längs der tetragonal an- geordneten Axen.
anei aufein-
1. Schiebung längs einerQuerrichtung parallel zur Sym- metrieebene.
Die Resultirende der letzten zwei Schie- bungen.
Keine.
$\frac{1}{2}$ Schiebung langs der tetragonal an- geordneten Axen. Keine.
Wie im Typus $60 \beta_{2}$.

\section{Trigonale Gruppe.}

Die Typen 42, 43, 44, 45, 46 und $47(15,16,19,20,23$ und 24 nach $S$ o h n cke) liefern kein doppeltes System.

\begin{tabular}{l||c|c|l}
$48 \mathrm{~b}_{1}$ & Typ. 48 (17 n. S o h n c k e) & $\begin{array}{c}\text { Durch năchste dreizählige Axen } \\
\text { derselben Art gelegt. }\end{array}$ & Keine. \\
$48 \mathrm{~b}_{2}$ & - & - & $\frac{1}{2} \quad \begin{array}{c}\text { Schiebung längs } \\
\text { einer dreizähl.Axe. }\end{array}$
\end{tabular}




\begin{tabular}{|c|c|c|c|}
\hline Nr. & $\begin{array}{l}\text { Einfaches S o h n ck e'sches } \\
\text { System, von welchem das } \\
\text { doppelte System abgeleitet ist }\end{array}$ & $\begin{array}{c}\text { Lage einer Symmetrieebene des } \\
\text { doppelten Systems }\end{array}$ & $\begin{array}{l}\text { Schiebung, wenn eine } \\
\text { erforderlich ist, die enan- } \\
\text { tiomorphen Systeme anf } \\
\text { beiden Seiten der Sym- } \\
\text { metrieebene einander } \\
\text { gegenuiberzustellen }\end{array}$ \\
\hline $48 b_{3}$ & Typus 48 ( 17 n. Sohncke) & $\begin{array}{l}\text { Durch übernächste gleiche } \\
\text { Axen gelegt. }\end{array}$ & Keine. \\
\hline $48 b_{4}$ & $\rightarrow$ & 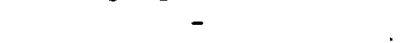 & Wie in Typus $48 \mathrm{~b}_{2}$ \\
\hline $48 b_{5}$ & - & $\begin{array}{l}\text { Senkrecht zu den dreizähligen } \\
\text { Axen. }\end{array}$ & Keine. \\
\hline $49 b_{1}$ & $-49(21$ n. Sohncke) & $\begin{array}{l}\text { Senkrecht zu dreizäbligen Axen } \\
\text { und zweizählige Axen ent- } \\
\text { haltend. }\end{array}$ & Keine. \\
\hline $49 \mathrm{~b}_{2}$ & - & $\begin{array}{l}\text { Senkrechtzu dreizăhligen Axen } \\
\text { und mitten zwischen zwei- } \\
\text { zähligen Axen verschiedener } \\
\text { Art gelegen. }\end{array}$ & Keine. \\
\hline $\mathbf{5} 0 \mathbf{b}_{1}$ & $-50(25 \mathrm{n}$. Sobncke) & Wie in $49 b_{1}$. & Keine. \\
\hline $50 \mathrm{~b}_{2}$ & - & $-\quad-49 b_{2}$ & Keine. \\
\hline $\mathbf{s} 1 \mathbf{b}_{1}$ & - 51 (18 n. Sohncke) & $\begin{array}{l}\text { Durch năchste dreizaihligeDreh- } \\
\text { axen gelegt. }\end{array}$ & Keine. \\
\hline $51 b_{2}$ & - & - & $\begin{array}{l}\frac{1}{2} \text { Schiebung längs } \\
\text { einer dreizăhligen } \\
\text { Axe. }\end{array}$ \\
\hline
\end{tabular}

Typus 52 (22 nach Sohncke) liefert kein doppeltes System ausser jenen in Tabelle 1.

\section{Rhombische Gruppe.}

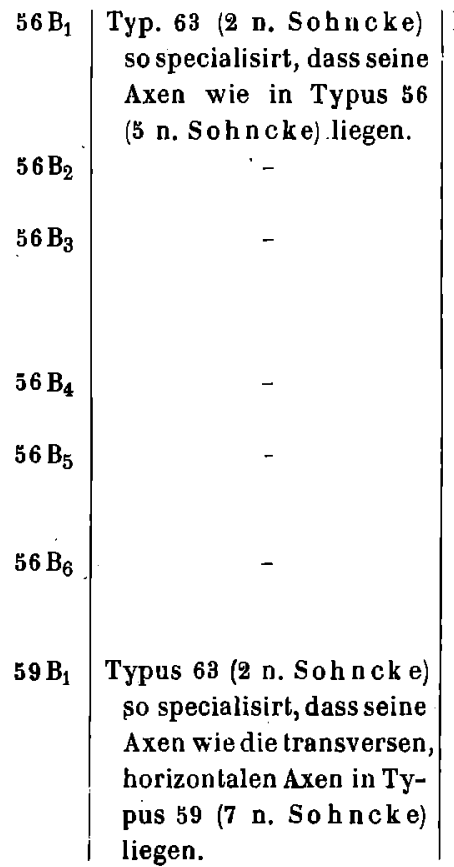

Keine.

Mitlen zwischen zwei aufeinander folgende, zuletzt beschriebene Ebenen verschiedener Art.

Wie in $56 \mathrm{~B}_{1}$ gelegt, so dass sie die Axen des einen oder des anderen der beiden vorhandenen Axenpaare enthält. $\frac{1}{2}$ Schiebung längs der Axen.

Keine.

1 Schiebung Jängs der Axen.

$\frac{1}{2}$ Querschiebung längs der Symmetrieebene.

Die Resullirende der zwei zuletzt genannten. 


\begin{tabular}{|c|c|c|c|}
\hline Nr. & $\begin{array}{l}\text { Einfaches Bobncke'sches } \\
\text { System, von welchem das } \\
\text { doppelte System abgeleitet ist }\end{array}$ & $\begin{array}{l}\text { Lage einer Symmetrieebene des } \\
\text { doppelten Systems }\end{array}$ & $\begin{array}{c}\text { Schiebung, wenn eine } \\
\text { erforderlich ist, die enan- } \\
\text { tiomorphen Systeme auf } \\
\text { beiden Seiten der Sym- } \\
\text { metrieebene einander } \\
\text { gegenüberzustellen } \\
\end{array}$ \\
\hline $59 \mathrm{~B}_{2}$ & $\begin{array}{l}\text { Typus } 63 \text { (2 n. Sohncke) } \\
\text { etc. wie vorher. }\end{array}$ & $\begin{array}{l}\text { Wie in } 56 \mathrm{~B}_{1} \text { gelegt etc. wie } \\
\text { vorher. }\end{array}$ & $\begin{array}{l}\frac{1}{2} \text { Schiebung längs } \\
\text { der Axen. }\end{array}$ \\
\hline $\mathbf{5} 3 \mathbf{B}_{1}$ & $\begin{array}{l}\text { Typus } 62 \text { (3 n. So hncke) } \\
\text { so specialisirt, dass seine } \\
\text { Axen wie die des Typ. } 53 \\
\text { (6 n. Sohncke) liegen. }\end{array}$ & Wie in $56 \mathrm{~B}_{1}$. & Keine. \\
\hline $53 \mathbf{B}_{2}$ & - & Wie in $56 \mathrm{~B}_{3}$. & Keine. \\
\hline $53 \mathbf{B}_{3}$ & - & - & $\begin{array}{l}\frac{1}{2} \text { Schiebung lángs } \\
\text { der Axen. }\end{array}$ \\
\hline $53 \mathbf{B}_{4}$ & 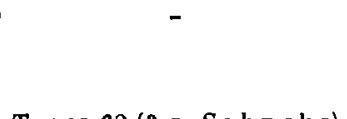 & - & $\begin{array}{l}\frac{1}{2} \text { Querschiebung } \\
\text { längs der Symme- } \\
\text { trieebene. }\end{array}$ \\
\hline $57 B_{1}$ & $\begin{array}{l}\text { Typus } 62 \text { (3 n. So b n ck e) } \\
\text { so specialisirt, dess seine } \\
\text { Axen wie jene des Typ.57 } \\
\text { (9 n. So h n ck }) \text { ) liegen. }\end{array}$ & Wio in $56 B_{1}$. & Keine. \\
\hline $58 \mathrm{~B}_{1}$ & $\begin{array}{l}\text { Typus } 62 \text { (3 n. So hn cke) } \\
\text { so specialisirt, dass seine } \\
\text { Axen wie jene der Typen } \\
58 \text { oder } 60 \text { (11 oder } 10 \mathrm{n} \text {. } \\
\text { So h n k } \text { ) liegen }{ }^{*} \text { ). }\end{array}$ & Durch nächste Drehaxen gelegt. & Keine. \\
\hline $58 B_{2}$ & - & - & $\begin{array}{l}\frac{1}{2} \text { Schiebung längs } \\
\text { der Axe. }\end{array}$ \\
\hline $58 B_{3}$ & - & - & $\begin{array}{l}\frac{1}{2} \text { Querschiebung } \\
\text { längs der Symme- } \\
\text { trieebene. }\end{array}$ \\
\hline $59 B_{3}$ & $\begin{array}{l}\text { Typus } 64 \text { (4 n. Sohncke) } \\
\text { so specialisirt, dass seine } \\
\text { Axen wie die zur Ebene } \\
\text { von Soh ncke's Zeich- } \\
\text { nung des Typus } 59 \text { (7 n. } \\
\text { Sohn cke) senkrechten } \\
\text { Axen liegen. }\end{array}$ & $\begin{array}{l}\text { Horizontal gelegtin Soh ncke's } \\
\text { Fig. } 7 \text { und nächste Drehaxen } \\
\text { enthaltend. }\end{array}$ & Keine. \\
\hline $59 \mathrm{~B}_{4}$ & - & - & $\begin{array}{l}\frac{1}{2} \text { Schiebung lángs } \\
\text { der Axen. }\end{array}$ \\
\hline $\mathbf{5 9 B}_{5}$ & - & - & $\begin{array}{l}\frac{1}{2} \text { Querschiebung } \\
\text { längs der Symme- } \\
\text { trieebene. }\end{array}$ \\
\hline $59 B_{6}$ & $\bar{\vdots}$ & - & $\begin{array}{l}\text { Die Resultirende der } \\
\text { zwei zuletzt ge- } \\
\text { nannten. }\end{array}$ \\
\hline
\end{tabular}

*) Die relative Lage von Axen, welche die gleiche Richtung haben, ist identisch in diesen zwei Systemen. 


\begin{tabular}{|c|c|c|c|}
\hline Nr. & $\begin{array}{l}\text { Einfaches So h c ke'sches } \\
\text { System, von welchem das } \\
\text { doppelte System abgeleitet ist }\end{array}$ & $\begin{array}{l}\text { Lage einer Symmetrieebene des } \\
\text { doppelten Systems }\end{array}$ & $\begin{array}{l}\text { Schiebung, wenn eine } \\
\text { erforderlich ist, die enan- } \\
\text { tiomorphen Systeme auf } \\
\text { beiden Seiten der Sym- } \\
\text { metrieebeze einander } \\
\text { gegenüberzustellen }\end{array}$ \\
\hline $61 B_{1}$ & $\begin{array}{l}\text { Typus } 64 \text { ( } 4 \mathrm{n} \text {. Sohncke) } \\
\text { sospecialisirt, dass seine } \\
\text { Axen wie die Axen in } \\
\text { eine r Richtung in Ty- } \\
\text { pus } 61 \text { (8 n. Sohncke) } \\
\text { angeordnet sind. }\end{array}$ & $\begin{array}{l}\text { Durch zwei nächste Dreh- und } \\
\text { Schraubenaxen gelegt. }\end{array}$ & Keine. \\
\hline
\end{tabular}

Rechtwinklig-rhomboidisch-prismatische Gruppe.

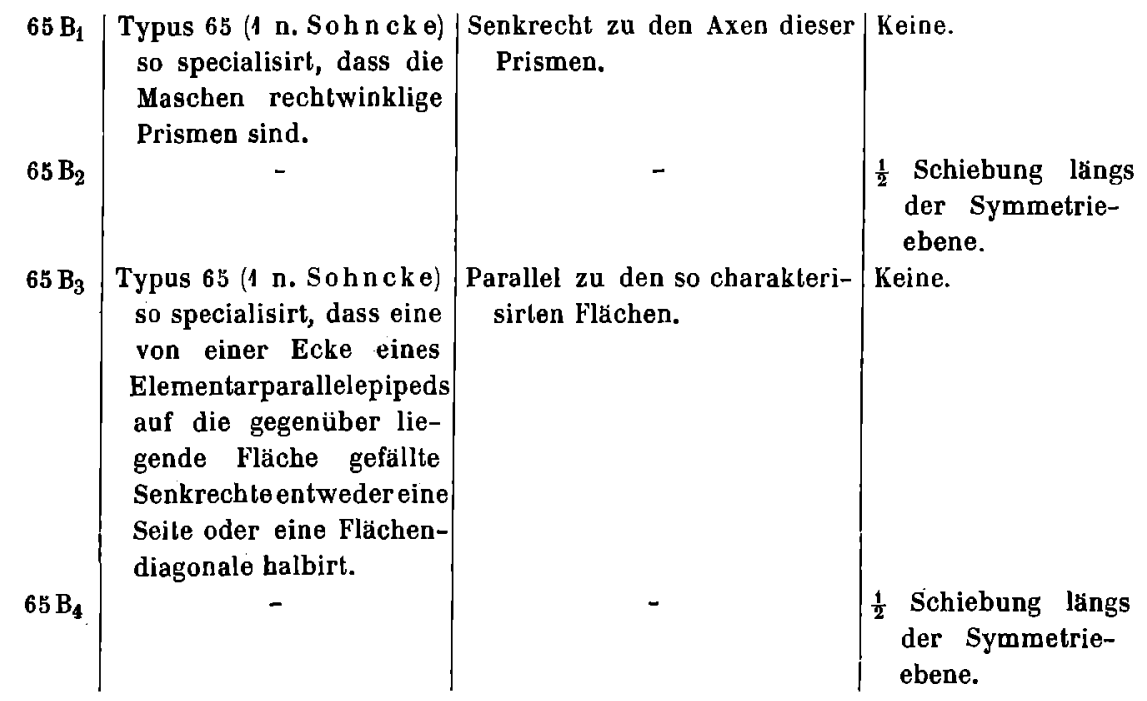

Jedem hier aufgefuhrten Typus eines doppelten Systems entsprechend giebt es einen Typus homogener Structur, welcher mit seinem eigenen Spiegelbilde identisch ist, dessen enantiomorphe Punktsysteme unendlich viel doppelte Systeme von diesem Typus bilden, und welcher Symmetrieebenen sowohl, als Deckbewegungen, nicht aber Symmetriecentren mit diesen doppelten Systemen gemein hat.

Die sechs Typen homogener Structur der kubischen Gruppe, deren doppelten Systeme in Tabelle $2 \mathrm{zu}$ finden sind, zeigen die tetraødrische Hemiëdrie der Glasse 30 in Sobncke's Verzeichniss der Krystallelassen*).

Die vier Typen homogener Structur der hexagonalen Gruppe zeigen die Hemimorphie der Vollflächigkeit der Glasse 17.

Die zwölf Typen homogener Structur der tetragonalen Gruppe, deren

*) Siehe diese Zeitschr. 20, 59 und 20, 467. 
gleiche Punkte Sohncke'sche Systeme bestimmen, die zu dieser Gruppe gehören, stellen die Hemimorphie der Classe $26^{*}$ ) dar. Jene zwölf, deren gleiche Punkte specialisirte S o h nck e'sche Systeme der rhombischen Gruppe ausmachen, zeigen die skalenoëdrische Hemiëdrie der Classe 24.

Von den elf Typen homogener Structur der trigonalen Gruppe zeigt die als $48 \mathrm{~b}_{5}$ bezeichnete die bipyramidale Tetartoudrie der Classe 16; sechs, nämlich die mit $48 b_{1}, 48 b_{2}, 48 b_{3}, 48 b_{4}, 51 b_{1}$ und $51 b_{2}$ bezeichneten, die Tetartomorphie der Classe 19, und jene vier, welche $49 b_{1}, 49 b_{2}, 50 b_{1}$ und $50 \mathrm{~b}_{2}$ heissen, die trigonotype Hemiëdrie der Classe 13*).

Die . 21**) Typen homogener Structur der rhombischen Gruppe zeigen die Hemimorphie der Classe 8 in Sohncke's Verzeichniss ${ }^{*} * *$ ).

Die vier Typen homogener Structur der rechtwinklig-rhomboidischprismalischen Gruppe zeigen die Hemiëdrie der Classe 4.

3. Doppelte Systeme, deren enantiomorphe Punktsysteme rechtwinklig gegen einander orientirt sind, and welche weder Symmetriecentren, noch Symmetrieebenen besitzen, und die Typen homogener Structur, in denen sie vorkommen.

Was die doppelten Systeme und homogenen Structuren betrifft, deren sie zusammensetzende einfache Systeme die mit c) bezeichnete relative Orientirung, nicht aber die mit a) oder die mit b) bezeichnete, baben + ), so mussen dieselben, wie gesagt, immer ein quadratisches Schnittpunktnetz einer Axengruppe baben. Sie enthalten Ebenen, welche sie in zwei enantiomorphe Hälften theilen, deren eine um $90^{\circ}$ um eine zu diesen Ebenen senkrechte Axe gedreht werden muss, damit enantiomorph-ähnliche Punkte direct einander gegenüber zu liegen kommen.

Die folgende Tabelle zeigt, welche verschiedenen Typen doppelter Sysleme, die weder Symmetriecentren noch Symmetrieebenentt) besitzen, von den Sohncke'schen Punktsyslemen herleitbar sind, und giebt in jedem Falle die Lage einer Ebene an, welche das doppelte System in zwei enantiomorphe Hälften theilt, und die Lage einer Axe, um

*) Es mag bemerkt werden, dass die aus den Typen 29,34 und 38 (29, 30 und 31 nach Sohn cke) abgeleiteten doppelten Systeme und ebenso die vom Typus 48 (17 nach S o hncke) hergeleiteten für sich genommen eine höhere Symmetrie haben, als die sie enthaltenden mindest-symmetrischen homogenen Structuren; es zeigen die ersteren die Vollflächigkeit der Classe 21, die letzteren die trigonotype Hemiëdrie der Classe 13.

**) Fe dorow zählt 22 Typen doppelter Systeme auf, aber der Verf. findet nur 24. Vergl. diese Zeilschr. 20, 49 und 50.

***) Die doppelten Systeme für sich besitzen die Symmetrie der Classe 6.

t) Siehe S. 42.

t) Dieses Wort ist im weiten Sinne gebraucht (s. Anmerk. S. 42). 
welche die eine Hälfte um $90^{\circ}$ gedreht werden muss, um entsprechende Punkte einander gegenuber zu stellen*).

Tabelle 3 der doppelten Systeme, welche weder Symmetriecentren noch Symmetrie日benen**) besitzen.

\begin{tabular}{|c|c|c|c|}
\hline Nr. & $\begin{array}{l}\text { Einfaches S ob nck e'sches } \\
\text { System, aus welchem das } \\
\text { doppelte System abgeleitet ist }\end{array}$ & $\begin{array}{c}\text { Lage einer Ebene, } \\
\text { welche das System in } \\
\text { enantiomorphe Hälften } \\
\text { theiJt }\end{array}$ & $\begin{array}{l}\text { Lage einer Axe, um welche eine } \\
\text { Hälfte um } 90^{\circ} \text { gedreht werden muss, } \\
\text { um der anderen gegenüberzuliegen }\end{array}$ \\
\hline $\begin{array}{l}63 \mathrm{c}(\mathrm{s} . \\
\text { Fig.14) }\end{array}$ & $\begin{array}{l}\text { Typus } 63 \text { (2 n. Sohncke) } \\
\text { so specialisirt, dass das } \\
\text { Schnittpunktnetz der } \\
\text { Axen quadratisch ist. }\end{array}$ & $\begin{array}{l}\text { Senkrecht zu den } \\
\text { Axen. }\end{array}$ & $\begin{array}{l}\text { Eine der Axen des Sohncke- } \\
\text { schen Systems. }\end{array}$ \\
\hline $\begin{array}{l}64 \mathrm{c}(\mathrm{s} . \\
\text { Fig.15) }\end{array}$ & $\begin{array}{l}\text { Typus } 64 \text { ( } 4 \text { n. Sohncke) } \\
\text { wie oben specialisirt. }\end{array}$ & $\begin{array}{l}\text { Senkrecht zu den } \\
\text { Axen. }\end{array}$ & $\begin{array}{l}\text { Eine der Drehaxen des } \\
\text { Sobncke'schen Systems. }\end{array}$ \\
\hline
\end{tabular}

Diese doppelten Systeme und die zwei Typen homogener Structur, in denen entsprechende Punkte solche doppelte Systeme bestimmen, gehören zum tetragonalen Systeme und zeigen die sphenoidische Tetartoëdrie der Classe 25 in Sohncke's Verzeichniss der Krystallclassen.

Es giebt keine anderen Typen homogener Struclur irgend welcher Art ausser den oben angegebenen.

Mit Rucksicht auf die Raụmeinheiten jener homogenen Structuren, welche mit ihren eigenen Spiegelbildern identisch sind, wird, wenn die Theilung des Raumes in Einheiten so ausgeführt wird, dass sie zu jedem der zwei einfachen Systeme jedes doppelten Systems, welches durch enantiomorph-ähnliche Punkte bestimmt wird, die gleiche Beziehung darbietet, - mit anderen Worten, wenn die Structur, nachdem die Raumtheilung hinzugekommen, nach wie vor mit ihrem eigenen Spiegelbilde identisch ist, - eine weitere Symmetrie der Raumlheilung dargestellt sein.

Denn damit die Raumtheilung mit den enantiomorphen einfachen Systemen in gleicher Beziehung stehen kann, muss sie offenbar die Symmetriecentren und Symmetrieebenen der Structur besitzen.

Um dies zu illustriren, sind drei Schnitte der möglichen Eintheilung dreier homogener, mit ihren Spiegelbildern identischer Structuren in Raumeinheiten beigegeben; alle drei sind vom Typus 48 (17 nach Sohncke) wie die fruher abgebildete Eintheilung $\left.{ }^{* * *}\right)$.

Im ersten Schnitte (Fig. 16) hat die Structur Symmetriecentren auf

*) Vier doppelte Systeme in Tabelle 2, nămlich $56 B_{1}, 59 B_{1}, 60 B_{1}$ und $61 B_{1}$ besitzen ausser ihren Symmetrieebenen noch Ebenen mit dieser Eigenschaft.

**) Dieser Ausdruck ist im weiten Sinne der Anmerk. auf S. 42 gebraucht.

***) Siehe S. 37 und Fig. 13. 
ihren dreizähligen Axen $A$, und der Schnitt ist senkrecht zu diesen Axen durch die Symmetriecentren geführt.

Im zweiten Schnitte (Fig. 17) hat die Structur Symmetrieebenen, welche benachbarte dreizählige Axen $A$ enthalten, und die enantiomorph-ähnlichen Punkte liegen in Bezug auf diese Ebenen einander direct gegenüber.

Im dritten Schnitle (Fig. 18) hat die Structur Symmetrieebenen, deren jede dreizählige Axen aller drei Arten enthält, und die enantiomorph-ähnlichen Punkte liegen bezüglich dieser Symmetrieebenen einander direct gegentuber.

Diese Schnitte mögen mit dem Schnitte (Fig. 13) einer möglichen Eintheilung einer Structur verglichen werden, deren gleichartige Punkte auch Punktsysteme vom Typus 48 bilden, welche aber nicht auch die neue Eigenschaft besitzt, mit ihrem eigenen Spiegelbilde identisch zu sein.

\section{Singuläre Punktsysteme.}

Alle durch Schaaren gleichartiger Punkte in irgend einer gegebenen homogenen Structur bestimmten Punktsysteme sind nothwendiger Weise vom gleichen Typus, nämlich dem durch die Deckbewegungen der Structur charakterisirten; diese Deckbewegungen sind allen Punktsystemen gemeinschaftlich. Einige Punktsysteme jedoch bestehen aus weniger Punkten als andere, und die Lagen, welche die Punkte der so ausgezeichneten Systeme inne haben, sind symmetrischer als die von den Punkten der anderen Punktsysteme der Structur besetzten.

So nehme man irgend einen Punkt auf einer beliebigen $m$-zähligen Drehaxe einer homogenen Structur und fuhre die Deckbewegungen der Structur aus, so dass man das Punktsystem findet, welches die Lagen der diesem gewählten Punkte gleichartigen Punkte markirt. Es ist klar, dass das Zahlenverbältniss der Punkte dieses Systems zu denen eines Punktsystems derselben Structur, dessen Punkte keine speciellen Lagen einnehmen, im Allgemeinen 1: $m$ sein wird; mit anderen Worten: Jeder Punkt eines solchen Systems kann als das Erzeugniss der Vereinigung von $m$ Punkten betrachtet werden, die gleichweit von irgend einer der gleichen $m$-zähligen Axen abstehen.

Wenn der gewäblte Punkt im Schnittpunkte zweier Drehaxen liegt, einer $m$-zähligen und einer $n$-zähligen, so werden sich im Allgemeinen die Punkte des von ihm erzeugten Punktsystems, wenn die Deckbewegungen der Struetur ausgeführt werden, zu den Pükten eines Punktsystems, welche keine speciellen Lagen einnehmen, verhalten wie 1: $m n$.

In gleicher Weise wird in den Fällen, wo der erzeugende Punkt der Schnitlpunkt von drei Drehaxen, einer $m$-zähligen, einer $n$-zähligen und einer $p$-zähligen, und die Bewegung um e in e Axe nicht die Resultirende 
aus den Bewegungen um die beiden anderen Axen ist, das Verhältniss $1: m n p$ sein.

Da nun alle Punktsysteme einer homogenen Structur dasselbe System der Deckbewegungen gemein haben, so ist klar, dass für eines derselben, welches aus weniger Punkten als andere besteht, irgend eine Deckbewegung keine Aenderung in der Lage einiger Punkte dieses Punktsystems bewirken muss, wăbrend sie im Allgemeinen die Lagen aller Punkte des Punktsystems verändert. Und diese Deckbewegungen mussen Drehungen sein, denn eine Schraubung sowohl als eine Schiebung bewegen immer jeden Punkt in einer Structur, auf welche sie angewendet werden.

Folglich mússen die Punkte irgend eines Sohncke'schen Punktsystems, welches aus weniger Punkten besteht als die meisten Punktsysteme derselben homogenen Structur, auf Drehaxen der Structur liegen, vielleicht aucb, wie in den oben erwähnten Fällen, in den Schnittpunkten zweier oder mehrerer Drehaxen.

Weiter sind die doppelten Systeme in einer homogenen Structur, die mit ihrem eigenen Spiegelbilde identisch ist, wie die sie zusammensetzenden einfachen Systeme alle von einem einzigen Typus, dessen Art jedoch sowohl durch die Lagen der Symmetriecentren oder Symmetrieebenen der Structur, als auch durch ihre Deckbewegungen bestimmt ist.

In einigen homogenen Structuren, welche diese hinzukommende. Eigenschaft besitzen, kommen jedoch doppelte Systeme vor, die nur aus einem einzigen einfachen Systeme bestehen oder, bestimmter ausgedruckt: in welchen die zwei einfachen Systeme zusammengefallen. sind. Diese doppelten Systeme besitzen infolge dieser Vereinigung offenbar halb so viel Punkte.

Die homogenen Structuren, welche singuläre Punktsysteme dieser Arl enthalten, sind jene, welche Symmetriecentren haben und jene, welche die Art der Symmetrieebenen besitzen, auf deren beiden Seiten enantiomorphähnliche Punkte direct einander gegenüberliegen; ebenso jene, in welchen die enantiomorphen Punktsysteme rechtwinklig gegen einander orientirt sind $\left.{ }^{*}\right)$.

Einige homogene Structuren besitzen, wie wir gesehen, mehr als eine einzige der eben erwähnten Eigenschaften; aber wenn dies der Fall ist, tritt kein weiteres Zusammenfallen der Punkte ein ausser dem, welches der Besitz einer einzigen solchen Eigenschaft in sich schliesst.

Wenn Symmetriecentren vorhanden sind, so liegen dieselben zuweilen auf Drehaxen, zuweilen nicht. Wenn durch ein Symmetriecentrum keine Drehaxe geht, so verhält sich die Punktzahl des doppelten Systems, welches aus demselben entsteht, wenn man die Deckbewegungen der Structur aús-

*) Siehe S. 58. 
fuhrt, zu der eines anderen doppelten Systems, dessen Punkte keine specielle Lagen haben, wie $1: 2$. Wenn das erzeugende Symmetriecentrum auf einer $m$-zähligen Drehaxe und sonst auf keiner liegt, wird das Verhältniss 1:2m sein. Wenn es im Schnittpunkte einer $m$-zähligen und einer $n$-zähligen Drehaxe liegt, wird das Verbältniss 1: $2 m n$ sein u. s. w.

Symmetrieebenen begleiten zuweilen, wie wir gesehen, Symmetriecentren und sind zuweilen allein vorhanden. In jedem Falle wird die Symmetrie ebene, wenn sie nur derart ist, dass auf ihren beiden Seilen die enantiomorph-ähnlichen Punkte einander direct gegenúberliegen, gan z aus singulären Punkten bestehen; mit anderen Worten: ein Punktsystem, welches aus einem in derselben gelegenen Punkte dadurch entsteht, dass man die Deckbewegungen der homogenen Structur ausfuhrt, wird aus weniger Punkten bestehen als die doppelten Punktsysteme, deren Punkte keine speciellen Lagen in der Structur einnehmen.

Wenn der erzeugende Punkt in der Symmetrieebene nicht auf einer Drehaxe liegt, wird sich die Zahl der Punkte des erzeugten Systems zu der eines doppelten Systems der Structur, dessen Punkte keine speciellen Lagen haben, wie 1:2 verhalten. Wenn der erzeugende Punkt in der Symmetrieebene auf einer einzigen, $m$-zähligen Drehaxe liegt und auf keiner anderen weiter, wird das Verhältniss 1:2 $m$ sein; wenn er auf zwei Drehaxen, einer $m$-zähligen und einer $n$-zähligen, und sonst auf keiner anderen liegt, 1:2mn u. s. f.

In den oben beschriebenen zwei Typen homogener Siructur, in welchen enantiomorphe Punktsysteme rechtwinklig gegen einander orientirt sind ${ }^{*}$ ), sind die Punkte, in welchen die quasi-tetragonalen Axen Ebenen scbneiden, die mitten zwischen zwei nächsten Querebenen liegen, welche bezüglich Punkte von zwei enantiomorphen Punktsystemen enthalten, singuläre Punkte der hier betrachteten Art. Denn sie liegen auf zweizähligen Axen, auch sind sie Punkte des Zusammenfallens von enantiomorph-correspondirenden Punkten.

Folglich verhält sich die Zahl der Punkte der doppelten Systeme, zu denen sie gehören, zu jener der Punkte•der doppelten Systeme der Structur, welche keine speciellen Lagen einnehmen, wie $1: 4$.

Die in dieser Abhandlung erbaltenen Resultate können folgendermassen zusammengefasst werden:

1. In irgend einer, oben definirten, homogenen Structur haben gleichartige Punkte eine symmetrische Anordnung von einem bestimmten, der Structur eigenthumlichen Typus.

2. Wenn alle Typen symmetrischer Anordnung, welche fur die Theile homogener Structuren möglich sind, aufgesucht werden, so findet man in

*) Siehe S. 58 . 
jedem Falle, dass sie die Symmetrie der einen oder anderen der 32 geometrisch möglichen Classen der Krystallsymmetrie haben. Ein verhältnissmässig grosser Theil der Typen ist mit seinem eigenen Spiegelbilde identisch.

3. Diese Typen zerfallen ferner in sieben Gruppen; Typen derselben Gruppe sind durch gemeinschaftliche Eigenschaften mit einander verknüft, welche den Typen der ubrigen Gruppen nicht zukommen *).

4. Die Thatsache, dass die Krystalle fast alle, wenn nicht thatsächlich alle 32 geometrisch möglichen Arten der Symmetrie zeigen, ist ein gewichtiges Zeugniss dafür, dass die Krystalle homogene Structuren nach obiger Definition sind; dieselben sind theils mil ihren eigenen Spiegelbildern idenlisch, theils nicht. Sie ist jedoch kein Beweis fürdie Beschaffenheit der Atome oder Molekule oder auch nur für deren Existenz.

5. Wenn jedoch die Existenz von Atomen als auf anderem Wege erwiesen angenommen werden kann, und in einem gegebenen Falle das Zahlenverhältniss der verschiedenen vorhandenen Atome bekannt ist, und wenn man weiter weiss, dass gleichartige Atome gleichartige Lagen in der Structur einnehmen, so ist einiges Licht auf die relative Anordnung der verschiedenen Atome geworfen durch die Lage der singulären Punk tsysteme in den homogenen Structuren.

Ein weiterer Beweis dafür, dass Krystalle homogene Structuren nach obiger Definition der Homogenität sind, wird durch die Thatsacbe erbracht, dass die Tetartoëdrie der Krystallform gewöhnlich mit der Drehung der Polarisationsebene des Lichtes verbunden ist. Denn wenn wir die Punktsysteme jener homogenen Structuren prüfen, welche Tetartoëdrie zeigen, so sehen wir, dass die Punkte meistens eine deutlich spiralförmige Anordnung haben, und, wie wohlbekannt, ist eine spiralförmige Structur nöthig um die erwähnte optische Eigenschaft zu erklären.

Hillfield, Muswell Hill, London $\mathbf{N}$.

*) Siehe S. 37 . 